\title{
Shear wave velocity structure beneath North-Western Himalaya and adjoining areas
}

\author{
Ramees R. Mir ${ }^{1, *}$, Imtiyaz A. Parvez ${ }^{1}$, Vinod K. Gaur ${ }^{1}$ \\ ${ }^{1}$ CSIR - Fourth Paradigm Institute, Wind Tunnel Road, Bangalore-37, India \\ *Corresponding author: \\ Email address: ramizmir752@gmail.com \\ Phone: +918025051345
}

Note: This is a non-peer reviewed preprint submitted to EarthArXiv. This work was initially submitted to a scientific journal in April 2019 and was rejected after peer review. Modified afterwards, it is shared here particularly for discussion on the observation of the shallower Moho beneath the Kashmir Himalaya. Please feel free to contact the corresponding author for criticism, comments or questions. 


\section{Abstract}

1 Shear wave velocity structure, together with Moho depths have been estimated in northwestern

2 Himalaya, Hindu Kush and the Pamirs at a potential resolution of $0.5^{\circ} \times 0.5^{\circ}$ and at $1^{\circ} \times 1^{\circ}$ in the

3 surrounding area, by inverting fundamental mode Rayleigh wave group velocities calculated

4 from regional earthquake $(\Delta \leq 2500 \mathrm{~km})$ data, and also from their joint inversions with

5 teleseismic receiver functions at 38 of the 59 broadband stations in the region that provided the

6 data. The results yield shear-wave velocity structure of northwestern Himalaya extending from

7 Hindu Kush through Kohistan-Nanga Parbat to Kashmir Himalaya, as well as the Pamirs in the

8 north and Lesser Himalaya along with the foreland basin including the Hazara syntaxis in the

9 south. In particular, shear-wave velocity profiles illuminate a) the deeper root zone structures of

10 the main geomorphic features, b) a pervasive low velocity layer (Vs $\sim 3.1 \mathrm{~km} / \mathrm{s}$ ) at $\sim 30 \mathrm{~km}$ depth

11 beneath the NW Himalaya. Another notable result is the distinctly shallower Moho beneath the

12 Kashmir Himalaya apparently segmented by arc-normal shear zones that cross the rupture zones

13 of the 1905 Kangra and the 2005 Kashmir earthquakes, in turn, marked by the current epoch

14 seismicity. The obtained shear-wave velocity model of the region will be used for precise

15 location of microseismicity, modelling strong ground motion, and as an apriori for future high

16 resolution studies.

Keywords: North-Western Himalaya; Rayleigh-wave group velocity; shear-wave velocity structure; Moho depths. 


\section{Introduction}

17 Elastic moduli and densities of materials at various depths in the earth are the most evocative

18 descriptors of earth structure which, in turn, forms the basic perspective for formulating plausible

19 hypotheses to model earth evolution in terms of past and ongoing tectonic processes as well as to

20 quantify hazard. These quantities being the determinants of wave speeds, are indirectly estimated

21 from the latter. The velocity of shear waves, in particular, proves to be a good discriminant both

22 in relation to rigidity of the material as well as deformation induced anisotropy of rock materials

23 at depth as proxies of past patterns of deformation. Determination of the shear-wave velocity

24 structure of the earth at various scales and at increasing resolution in regions of complex tectonic

25 activity such as Himalaya-Tibet, has, therefore, been the focus of seismological research since

26 the mid twentieth century. The advent and growing expansion of broadband seismic stations

27 around the globe, significantly advanced this trend and fueled developments of incisive

28 analytical frameworks, notably tomographic imaging of the earth in three dimensions, which

29 have been used in this work.

30 Convergence vectors in northwestern Himalaya have been found to be different from those in

31 Central and Nepal Himalaya (Schiffman et al. 2013; Jade et al. 2020), as might be expected

32 because of its location at the extremity of the arc, close to the Chaman-Herat transform boundary

33 along which India slides northeastward, adding along-arc stresses to those arising from the arc-

34 normal convergence. Schiffman et al. (2013) and Jade et al. 2020 also determined that the

35 interseismic locked zone in northwestern Himalaya is $\sim 145-150 \mathrm{~km}$ wide unlike its $\sim 100 \mathrm{~km}$

36 width in central and Nepal Himalaya. The work presented here was motivated by the need to

37 obtain high resolution shear velocity structure of the region spanning the northwestern extremity

38 of the Himalaya to serve as a base-map for investigating its finer structure, carved by more 
39 complex convergence processes, notably the Moho and intra-crustal features, as well as

40 quantification of the resulting hazard. Accordingly, we analyzed data, recorded at 59 broadband

41 stations in and around the region (Figure 1) including 9 new ones in Kashmir Himalaya. The

42 resulting three-dimensional shear wave velocity structure obtained by inverting fundamental

43 mode Rayleigh wave group velocities calculated from data along 2628 criss-crossing source-

44 receiver paths, as well as Moho depths, constitute the new results presented here.

45 The first such attempt for the Himalayan region as a part of the Indian subcontinent, was made

46 by Mitra et al. (2006) who produced fundamental mode Rayleigh wave dispersion data of the

47 region at a resolution of $7.5^{\circ}$. This was followed by Acton et al. (2010) who, using a larger data

48 set which had become available by then, improved the resolution to $3^{\circ}$, and also obtained shear

49 wave velocity model of India and Tibet by inverting Rayleigh wave group velocities. This work

50 was further extended by Gilligan and Priestley (2018) who using an even larger data set,

51 extended their coverage to include most of Asia up to $50^{\circ}$ latitude. Their checkerboard results for

52 the $10 \mathrm{sec}$ period were able to resolve most of Himalaya and Tibet at a resolution of $2^{\circ}$, except

53 the northwestern Himalaya. Recently, Li et al. (2018) made a higher resolution $\left(0.8^{\circ} \times 0.8^{\circ}\right)$

54 shear wave velocity map of the Pamir and the Hindu Kush but stopped short of the northwestern

55 Himalaya north of the syntaxial bend. Maurya et al. (2016) also produced a $1^{\circ} \times 1^{\circ}$ shear wave

56 velocity structure of the Indian lithosphere including the Himalaya, but claimed a resolution of

$57200 \mathrm{~km}$ only. Results of this study fill the gap left by earlier ones, and shed new light on the

58 structure of this complex region.

59 The 9 broadband stations installed in Kashmir Himalaya for this study, provided data for over

60 half of the 2628 source-receiver paths, yielding fundamental mode Rayleigh wave group

61 velocities from 8 to 60 seconds that allowed determinations of shear wave velocities over 
62 northwestern Himalaya, the Hindu Kush, the Pamir, and in the surrounding region covering the

63 western Tarim basin, the west-central Himalaya, southern Tien Shan and western Pakistan.

64 Shear wave velocity structure beneath 38 stations for which data were available, were also

65 determined independently from joint inversion of teleseismic receiver functions with Rayleigh

66 wave group velocities. These spot values compare well with those inverted from Rayleigh wave

67 group velocities alone, showing an average correlation coefficient of $0.7-0.9$ for upper and

68 middle crust. Elsewhere also, in the region common with that investigated by Li et al. (2018), the

69 correlation coefficient is $\sim 0.7$, even though the nonlinear Bayesian inverse used by us in

70 estimating shear-wave velocities was different from that employed by Li et al. (2018). Our

71 preference for using the Bayesian inverse was dictated by its superior performance demonstrated

72 by comparison of inversion results (see section 2) of a data set common with that used by

73 Maurya et al. (2016) using both the Bayesian inverse as well as the linearized least-square

74 inversion code of Herrmann and Ammon (2004). Since, seismic network is rather sparse in the

75 region because of challenging terranes, availability of this basic knowledge product is expected

76 to prove helpful in designing experiments to address the many puzzles and problems of the 77 region.

\section{Data and Methodology}

78 The data used in this study come from regional earthquakes $(\Delta \leq 2500 \mathrm{~km})$ recorded at 59

79 broadband seismic stations (Figure 1). Of the 9 Kashmir Himalaya stations equipped with

80 Nanometrics Trillium 120P broadband seismometers, all installed at hard rock sites, 3 were

81 located on the southwestern flank of the Kashmir basin along the foothills of the Pir Panjal

82 range, 5 around the central and northeastern Kashmir basin, and one near Drass in the Zanskar,

83 northeast of the valley. All data were recorded at 100 samples per second and time stamped with 
84 continuous Global Positioning System with an error of the order of $10^{-3} \mathrm{~s}$. Data from the

85 international agencies of Incorporated Research Institutions for Seismology (IRIS), French

86 Seismologic and Geodetic Network (RESIF) and German Seismic Network (GEOFON) were

87 downloaded and preprocessed using Obspy (Beyreuther et al. 2010). The IRIS sites included, 13

88 broadband stations of the XG95 network (1995-1996) around Nanga Parbat, equipped with

89 Guralp CMG-3 broadband seismometers with velocity sensitivity of $1500 \mathrm{Vs} / \mathrm{m}$ and a flat

90 response range of $40 \mathrm{~s}-16 \mathrm{~Hz}$, and one each in Kabul (KBL) and Nilore(NIL) equipped with

91 Nanometrics Trillium 240s and STS-2 respectively. The 19 station YT network operated by

92 RESIF from January to December 2001 were equipped with Guralp CMG-3 and STS-2

93 instruments, whilst the two GEOFON sites at Kabul and Aksay in Kyrgyzstan were equipped

94 with STS-2 seismometers. Additionally, we used data from the Indian stations at Leh and Hanle

95 installed by the Indian Institute of Astrophysics with Guralp CMG-3 instruments, and 12

96 broadband stations of the National Centre for Seismology (NCS). Records of the revised regional

97 earthquakes $(\Delta \leq 2500 \mathrm{~km})$ from the USGS (United States Geological Survey) earthquake catalog

98 showing $\leq 20 \mathrm{~km}$ position errors were extracted as 30 minute time series. All vertical-component

99 seismograms duly corrected for their respective instrument responses, were bandpass filtered

100 between $0.008-0.2 \mathrm{~Hz}$, and converted into the SAC (Seismic Analysis Code, Goldstein and

101 Snoke, 2005) format.

102 Fundamental mode Rayleigh waveforms $\mathrm{S}\left(\omega_{\mathrm{k}}\right)$ centered at closely spaced frequencies $\omega_{\mathrm{k}}$ in the

103 band, were extracted for each source-receiver path, by filtering the corresponding Fourier

104 domain vertical seismograms through narrow Gaussian filters $e^{\left[-\alpha\left(\omega-\omega_{\mathrm{k}}\right)^{2}\right] / \omega_{k}^{2}}$ using the multiple

105 filter method (Dziewonski et al.1969; Herrmann1973), where the values of $\alpha$ which determines

106 the balance between the source-receiver distance and resolution, were taken from Herrmann's 
107 manual (Hermann and Ammon, 2004). The various frequency domain $\mathrm{S}\left(\omega_{\mathrm{k}}\right)$ waveforms were

108 then transformed into their time domains $_{\mathrm{k}}(\mathrm{t})$ counterparts to determine their average group

109 travel times $\mathrm{T}_{\mathrm{g}}\left(\omega_{\mathrm{k}}\right)$ along a given source-receiver path, taking as reference, the maximum

110 amplitude $a_{k}\left(\frac{d a_{k}}{d t}=0\right)$ of the corresponding time domain waveform $\mathrm{s}_{\mathrm{k}}(\mathrm{t})$. The set of travel

111 times $\mathrm{T}_{\mathrm{g}}\left(\omega_{\mathrm{k}}\right)$ dividing the corresponding source-receiver distance, yield the Rayleigh wave

112 fundamental mode dispersion data $\mathrm{V}_{\mathrm{Rg}}(\omega)$ along each of the criss-crossing vertical planes joining

113 the various sources and receivers. These were then inverted to produce a 2 dimensional Rayleigh

114 wave dispersion map of the region (Figures 2-3) for periods between 08 to 60 seconds, using the

115 two step, Fast Marching Surface-wave Tomography code (FMST) of Rawlinson and Sambridge,

116 (2005). Damping and smoothing parameters used in these inversions were chosen to be 0.5 and

1171.0 respectively, after extensive tests covering a wide range (0-500) of these values. Manual

118 picking of the fundamental mode dispersion at source-receiver distances of $\leq 2500 \mathrm{~km}$ along

119 with the use of the FMST which computes wavefronts using a finite-difference scheme, makes

120 the estimations more robust even in a highly heterogeneous medium, compared with the

121 traditional ray-tracing method (Rawlinson and Sambridge, 2004), and mitigates the blurring

122 effects of refraction and multi-pathing that begin to assume significance at source-receiver

123 distances $>5000 \mathrm{~km}$ (Ritzwoller et al. 2002).

124 In order to check the potential resolution of tomographic solutions, we performed synthetic 125 checkerboard tests using $0.5^{\circ} \times 0.5^{\circ}$ and $1.0^{\circ} \times 1.0^{\circ}$ square grid anomalies with two contrasting 126 velocities equal to $V_{R g}(\omega) \pm 0.66 \mathrm{~km} / \mathrm{s}$ assigned to alternate grids, where $V_{R g}(\omega)$ denotes the 127 average of all group velocities in the region at the frequency $\omega$. We then calculated synthetic 128 travel times for this prescribed velocity model produced by the same source-receiver sets for 129 which we had observed data, and inverted these, via subspace method equipped in FMST 
130 package, after contaminating each of the paths with random Gaussian noise having maximum

131 standard deviation of $0.54 \mathrm{~s}$. Whilst the fidelity with which the inverted solution correlates with

132 the originally prescribed model, in turn, determined by the azimuthal spread and density of

133 source-receiver paths through a particular grid, is generally regarded as proof of the claimed

134 resolution, the approach suffers from the fundamental ambiguity of inverse solutions. We further

135 tried to minimize the uncertainties by visually demarcating the region for which the $0.5^{\circ} \times 0.5^{\circ}$

136 anomaly recovering could be justifiably relied on, both by looking at the quality of reproduction

137 in the inverted checkerboard solutions for various periods as well as the azimuth spread - path

138 density data at the corresponding periods through each grid. Both these indicators for the 20

139 seconds period are shown in Figure 4.

140 We used the Neighborhood Algorithm (NA) (Sambridge1999a,b) as implemented by Yao et al.

141 (2008) to invert the Rayleigh wave dispersion data to obtain both the shear wave velocity with

142 respect to depth as well as Moho depths in the region. The NA performs the inversion by

143 calculating an ensemble of a-posteriori models from a given number of a-priori models generated

144 from a chosen one through a guided process of refinement. First, a number $\mathrm{n}_{\mathrm{s}}$ of random versions

145 of the a-priori model vector are generated by perturbing it by $10-15 \%$, and misfits with respect

146 to the 2-D dispersion data calculated for each of these perturbed models to produce an error

147 (misfit) surface. The sets of least misfits in the error surface is then used to select the best fitting

148 subset of $n_{r}$ models, each demarcated by Voronoi cells (Okabe et al. 2000). Each of these $n_{r}$

149 models is then used to generate the next suite of $n_{s}$ models through $\left(n_{s} / n_{r}\right)$ random walks in each

150 of the $n_{r}$ Voronoi cell, yielding an updated error surface. This process is iterated to home on to a

151 set of best fitting models where-after the entire set of parent and daughter models are inverted to

152 obtain an ensemble of a-posteriori models. 
153 We followed Sambridge (1999a, b) by creating a first set of 300 a-priori models by perturbing 154 the shear wave velocities of Maurya et al. (2016) beneath each grid of the region, to a maximum 155 of $\pm 0.8 \mathrm{~km} / \mathrm{s}$. The choice of Maurya et al's model as a basis for defining our a-priori model was 156 dictated by the large commonality of the data sets used by us. However, since Maurya et al. 157 (2016) had derived their shear wave velocity model from dispersion data available only above 16 158 sec period, we chose a higher range of perturbation $( \pm 0.8 \mathrm{~km} / \mathrm{s})$ to ensure that a larger possible 159 model space could be sampled. A-priori values of Moho depths beneath each grid were also 160 abstracted from Maurya et al's model by selecting the surface where the shear wave velocity 161 crossed the $4.2 \pm 0.2 \mathrm{~km} / \mathrm{s}$ value (e.g., Rai et al. 2006; Hazarika et al.2017; Mir et al.2017). 162 From this first suite of perturbed models we selected 50 best fitting ones, each demarcated in the 163 model space by Voronoi cells and defined by its misfit value. Next, we generated 2 new models 164 in each Voronoi cell through random walk, and isolated from amongst these, the next set of 50 165 best fitting models. These new points in the model space together with their parent models define 166 a new configuration of Voronoi cells and a corresponding misfit surface, thus obtaining a total of 167 32,200 a-priori models after 319 iterations (Figure 5). From these we obtained an ensemble of a168 posteriori models using the Bayesian Inverse. The one amongst these with the least covariance is 169 then adopted as the final model.

170 Shear wave velocity structure of the region thus calculated is shown in Figure 6, whilst the Moho 171 depths are shown in Figure 7. In order to check the reliability of this determination, we also 172 calculated the shear wave velocity structure beneath 38 sites for which data were available, by 173 joint inversion of teleseismic receiver functions with a weakly weighted (10\%) surface wave 174 dispersion data. These are compared for 8 stations in Figure 8. To add further constraints on 175 shallow structures beneath the Kashmir basin, we calculated fundamental mode Rayleigh wave 
176 group velocities for 3-8 sec period by cross-correlating ambient noise on vertical components of

177 seismograms recorded at 7 Kashmir basin stations. These data along with dispersion data from

178 earthquakes as described above were jointly inverted with calculated RFs at the respective sites.

179 Further, in order to appraise the relative quality of the above inversions, we also inverted the

180 surface wave dispersion data using the linearized least-square inversion code of Hermann and

181 Ammon, (2004) with two initial models: a modified AK135 model with a constant velocity of

$1824.48 \mathrm{~km} / \mathrm{s}$ from the surface down to $100 \mathrm{~km}$, and the shear velocity model of Maurya et

183 al.(2016). Compared with the result of the Bayesian inverse, both the other solutions were found

184 to produce a smoother structure blurring even the prominent geomorphic features.

185 Moho being a prominent discontinuity in the earth, its depth determines the Rayleigh wave

186 dispersion, in addition to the average crustal shear wave velocity. Accordingly, Moho depths in

187 the region were estimated by inverting Rayleigh wave group velocities beneath each point of the 188 grid, using the $4.4 \mathrm{~km} / \mathrm{s}$ surface in Maurya et al's shear wave structure for the region, as an a189 priori Moho, and allowing it to excurse within $4 \mathrm{~km}$ of this depth to seek the best fit. Posterior

190 Moho depths, thus determined with maximum uncertainty of $\pm 2.6 \mathrm{~km}$, are shown in Figure 7 191 along with its similarly color coded spot values determined by various authors (see section 3.3) 192 from inversion of receiver functions, some jointly with surface wave dispersion data. The 193 divergence between the map and the spot Moho values are generally seen to lie within these 194 uncertainties and vouch for confidence in the reliability of these estimations.

\section{Results}

195 The paper presents three sets of maps at $0.5^{\circ} \times 0.5^{\circ}$ grid corners covering the northwestern

196 Himalaya, the Hindu Kush and the Pamirs, and at $1^{\circ} \times 1^{\circ}$ grid points for the surrounding areas

197 (Figure 1). These are i) Rayleigh wave dispersion maps for 8-60 sec periods (Figures 2, 3), ii) 
198 shear wave velocity maps (Figure 6) up to a depth of $80 \mathrm{~km}$, and iii) Moho depth maps beneath

199 the entire region (Figures 7).

\subsection{Dispersion maps}

200 Grid-wise Rayleigh wave group velocity maps for the region were calculated from fundamental 201 mode Rayleigh waves for 10 different periods between 8 and $60 \mathrm{~s}$. Five of these between 10 and 20250 seconds are shown in Figures 2 and 3. Apart from clear identification of the low velocity 203 enclaves of western Tarim, Tadjik and the Himalayan foreland basins with the sediment 204 thickness map (correlation coefficient of -0.76 to -0.98) (Figure 2b) of Laske and Masters, 205 (1997), the 10 and $20 \mathrm{sec}$ maps also delineate the high velocity southern margin of the Hindu 206 Kush extending to the slightly lower velocity northwestern Himalaya from Nanga Parbat to 207 Himachal and Pamir to Tien Shan. Equally clearly, the latter define the Kunlun - AltynTagh 208 Fault (ATF) in the northeast and the Lesser Himalayan front in the south, across which velocities 209 are lower. In fact, the map captures even the eastern Tarim basin, the western Tadjik basin, the

210 northern Indus basin and the Fergana basin that lie well outside our well resolved region. The 211 northwest-southeast trending Himalayan terrain northeast of the foreland basin is clearly marked

212 by higher velocity at all periods whilst Tibet to its northeast, is significantly low at periods

213 higher than 30 seconds. A notable feature brought out by the shallow (10-30 sec) dispersion 214 maps is a high velocity $(\sim 3.1-3.2 \mathrm{~km} / \mathrm{s})$ enclave that geographically coincides with the location 215 of the higher density gneissic complexes of the northwestern Aravalli craton in peninsular India. 216 This anomalous region lies far to the south of our well resolved region, suggesting that it might 217 be an artefact. To check this possibility, we carried out a spike test, centered at this anomalous 218 area. The corresponding inverted solution is shown in Figure A2 and compared with a similar 219 spike test centered at a point in the well resolved area. The map shows that whilst the recovery of 
220 the former is only in the form of a diffused halo as expected from its location outside the well

221 resolved region, its unmistakable identification with the northwestern core of the Aravalli craton

222 at least up to periods of 20 seconds, testifies to the robustness of our maps.

\subsection{Shear-wave velocity structure}

223 The second set is the shear wave velocity structure of the region between $10-80 \mathrm{~km}$ depth (Figure

224 6) derived from the aforesaid dispersion maps. These were tested at 38 points of the region 225 against alternatively calculated shear wave velocity structure inverted by joint inversion of

226 surface wave dispersion data and teleseismic receiver functions. Eight of these are shown in

227 Figure 8. These figures distinguish 6 tectonic features of the region: The Hindu Kush and its high

228 velocity suture-zone oceanic crust bordering the subducting Indian lithosphere, the Nanga Parbat

229 and its Himalayan extension to the east, the Pamirs north of the Nanga Parbat syntaxis, Tibet, the

230 Tarim basin, and the Himalayan foreland basin. At $10 \mathrm{~km}$, high shear velocities $(\sim 3.4 \mathrm{~km} / \mathrm{s})$

231 mark out the Hindu Kush subduction zone, the Pamirs and the northwestern Himalaya against

232 the $\sim 3.1 \mathrm{~km} / \mathrm{sec}$ foreland basin, albeit with a small variance, but the deeper higher velocity $(\sim 3.8$

$233 \mathrm{~km} / \mathrm{s}$ ) cores of these features become more sharply defined at $20 \mathrm{~km}$. At $30 \mathrm{~km}$ the entire

234 northwestern Himalaya and Hindu Kush is characterized by low velocities $(\sim 3.2 \mathrm{~km} / \mathrm{s})$ except for

235 the Pamirs where the velocity reversal to a lower value occurs at $\sim 40 \mathrm{~km}$, whilst the western

236 Tarim basin to the northeast and the Himalayan foreland basin exhibit higher $(\sim 4.0 \mathrm{~km} / \mathrm{s})$

237 velocities, likely representing the oppositely underthrusting Asian and Indian plates respectively.

238 Further down beneath Pamir, shear velocities decrease whilst they continue increasing beneath

239 Nanga Parbat up to a depth of $60 \mathrm{~km}$ - the limit of our resolution. Another high velocity enclave

240 also appears at this depth around the Hazara syntaxial (HS, Figure 1) bend of the Lesser

241 Himalaya. 
242 The generation of 32200 models at each grid point with allowed Vs variation of $\pm 0.8 \mathrm{~km} / \mathrm{s}$

243 around the model parameters of Maurya et al.(2016) taken as an a-priori model, resulted in a

244 rich suite of posterior models using NA, whose error estimates, being free from the bias

245 introduced by regularization parameters, are expected to be more robust. Posterior error

246 estimates for each of the maps in Figure 6, which are $<0.45 \mathrm{~km} / \mathrm{s}$ up to a depth of $70 \mathrm{~km}$ in the

247 well resolved region, and $<0.46 \mathrm{~km} / \mathrm{s}$ up to $60 \mathrm{~km}$ depth in the surrounding region, are shown in

248 Figure A3. Shallower enclaves of high velocity beneath the Hindu Kush, Pamir, NangaParbat

$249(10-20 \mathrm{~km})$ have a maximum posterior error of $0.25 \mathrm{~km} / \mathrm{s}$, as also the low velocity layers

250 observed at $30 \mathrm{~km}$ beneath the Hindu Kush and NW Himalaya and at 40-50 km beneath the

251 Pamirs. For Kashmir Himalaya, which contributes more than $50 \%$ of the data used in this study,

252 the maximum error in $\mathrm{Vs}$ is $<0.4 \mathrm{~km} / \mathrm{s}$ to a depth of $100 \mathrm{~km}$.

\subsection{Moho depth}

253 The third set of maps shows Moho depths beneath the region (Figure 7) as well as Moho depth

254 variations along 6 profiles of the region (Figure 9) against the background of the corresponding

255 shear velocity structure. These are the best fitting surfaces $\mathrm{H}(\mathrm{x}, \mathrm{y})$ that reproduce the observed

256 dispersion $\mathrm{V}_{\mathrm{Rg}}(\omega)$ of fundamental mode Rayleigh waves, whilst conforming with the horizon

257 where the shear wave velocity is $4.2 \pm 0.2 \mathrm{~km} / \mathrm{s}$. Figure 9 also compares these Moho depths with

258 those obtained in earlier studies (Figure 7; Hazarika et al. 2014,2017; Gilligan et al. 2015;

259 Priestley et al. 2019; Rafi et al. 2019; Schneider 2014; Sharma et al. 2019), some using joint

260 inversion of receiver functions with surface wave dispersion data. Our results, however, conform

261 with Moho depths of the global CRUST1.0 model (Laske et al. 2013) only for NW Himalaya,

262 Ladakh, western Tarim basin and Himalayan foreland basin (Figure A4). The most notable

263 feature of Figure 7 is the along strike shallowing of Moho depths beneath the Kashmir Himalaya 
264 which beneath the Indus suture zone is $\sim 10 \mathrm{~km}$ shallower compared with its depth beneath arc-

265 normals both east and west of the Kashmir basin.

\section{Discussion}

266 The paper presents high resolution maps of i) fundamental mode Rayleigh wave group velocities,

267 ii) the shear wave velocity structure and iii) Moho depths beneath the northwestern Himalaya,

268 the Hindu Kush and the Pamir including the Himalayan foreland basin and the Hazara syntaxis

269 (Figure 1). A larger surrounding region also shows these 3 maps at lesser resolution but degrades

270 beyond the red boundary in Figure 1. The latter, whilst reproducing prominent features also

271 delineated by the most recent high resolution images of a part of this region (Li et al. 2018), add

272 further details, particularly to the deeper structure of southern Pamir. Notable new results

273 indicated in the dispersion maps but better delineated in the derived shear velocity maps,

274 highlight the higher shear wave velocity $(\sim 3.4 \mathrm{~km} / \mathrm{s})$ enclaves around a) the Hindu Kush-

275 Kohistan, b) the Nanga Parbat extending east-southeastwards to cover northwestern Himalaya,

276 c) the Pamirs and, d) the Ladakh batholiths, that monotonically increase right up to the Moho

$277(4.2-4.6 \mathrm{~km} / \mathrm{s})$, except for depth limited transitional reversals to $\sim 3.3-3.4 \mathrm{~km} / \mathrm{s}$, at $40 \mathrm{~km}$ beneath

278 the Pamirs and at $30 \mathrm{~km}$ in the region to its south (Figure 6).

\subsection{Intra-crustal low velocity layer}

279 The pervasive shear velocity reversal at $\sim 30 \mathrm{~km}$ beneath the entire northwestern Himalaya east

280 of the Hindu Kush, albeit reported for some other regions of the Himalaya (e.g., Guo et al. 2009;

281 Hazarika et al. 2014; Gilligan and Priestley 2018), appears counterintuitive. Its existence, if true,

282 would be expected to play a significant unifying role in the kinematics of the Himalaya. Since

283 we found clear signatures of this low velocity intra-crustal layer both in the surface wave

284 dispersion derived shear velocity structure of northwestern Himalaya and also in the joint inverse 
285 solutions of receiver functions (e.g. Figure 8 B,C,E), we made intensive forward modelling tests

286 all of which required its existence to fit the data, even as we have no means of discriminating

287 between the various hypotheses speculated to explain its occurrence such as fluidization or 288 occurrence of low velocity mineral phases.

\subsection{High shear-wave velocity enclaves}

289 The nearly identical shear velocity structure of the Hindu Kush, North-western Himalaya and 290 Ladakh, delineated by the Chaman-Herat Faults (CF, HF; Figure 1) that longitudinally bisects

291 the Hindukush, and the Main Karakoram Thrust skirting the Nanga Parbat to Ladakh, clearly 292 outlines the northern limits of the buried Indian crust. However, the 3 high velocity enclaves of 293 the Indian plate have differing structural settings. The westernmost Hindu Kush - Kohistan 294 region is expected to be bordered on the northwest by the obducted Tethys ocean crust (Searle et 295 al. 2001) that has apparently crept further southeastward giving the upper $20 \mathrm{~km}$ crust of the area 296 its higher velocity character. The higher velocity signature of northwestern Himalaya, locally 297 intensified beneath Nanga Parbat, on the other hand, reflects the existence of the wedge of Indian 298 plate Proterozoics and crystallines detached from the underthrusting Indian plate and stacked up 299 by the southward advance of Tibet over the Indian plate. Nanga Parbat with surface exposures of 300 migmatites and granulite grade rocks requiring rapid exhumation and showing field evidences of 301 along arc compression (Schneider et al. 1999), likely represent a modification of this process

302 caused by compressional stresses imposed by the nearby Herat transform fault at the western 303 extremity in conjunction with the likely existence of a NE-SW salient in the Indian plate 304 thrusting underneath it. The possible role of a low viscosity region beneath Nanga Parbat in 305 facilitating its past rapid rise has been discounted by Schneider et al. (1999) on the basis of their 306 field mapping that showed no evidence of any significant structure that would allow the implied 
307 large scale tectonic denudation. The nature of the low velocity material at $\sim 30 \mathrm{~km}$ beneath the

308 region, its origin and role in the kinematics of the Himalaya, therefore remains obscure as that of

309 'the mid-crustal conductor' at $\sim 10-25$ km depth beneath Nanga Parbat mapped by Park and

310 Mackie (1997).

311 The third prominent high velocity enclave represents the Ladakh batholith formed by subduction

312 of the Neo-Tethyan oceanic crust beneath the Eurasian plate. Field observations by Kumar

313 (2008) show that these calc-alkaline granitoids have been formed by several batches of coeval

314 mafic and felsic magmas. The higher surface shear velocity $(3.4-3.7 \mathrm{~km} / \mathrm{s})$ of this feature

315 indicates a higher mafic content albeit with variations along the range to the southeast.

316 Figure 6 also shows that the Hazara syntaxial region and the Potwar plateau to its southwest,

317 where shear velocities are low $(2.9-3.1 \mathrm{~km} / \mathrm{sec})$ in the first $20 \mathrm{~km}$, but, deeper down, increase

$318(\sim 3.8-4.0 \mathrm{~km} / \mathrm{s})$ upto $50 \mathrm{~km}$. Below this depth, the Potwar plateau immediately to its southwest,

319 is characterized by even higher velocities $(4.5-4.8 \mathrm{~km} / \mathrm{s})$ indicating the presence of a sharp rigid

320 salient of the underthrusting Indian plate. The arc normal swath connecting Nang Parbat and the

321 Hazara syntaxis and extending southwestward into the northern Potwar plateau, which is

322 seismically exhibited as a shear zone (Figure 1, inset) was most likely responsible for the

323 creation of the Hazara - Nanga Parbat syntaxes, assisted by the arc extremity compression whose

324 field expressions are clearly manifest in the Naga Parbat (Schneider et al., 1999)

\subsection{Moho depth}

325 Along- strike Moho depths in the region beneath the Indus-suture/Main Mantle Thrust, taken as

326 a reference, require the Moho to be shallower beneath the Kashmir Himalayan segment (Figures

327 7, 9).This segment, bounded by arc-normals that pass through the rupture zones of the 1905

328 Kangra and the 2005 Kashmir earthquakes which define the current epoch seismic gap, has not 
329 been ruptured by even a moderate earthquake since 1555 . Indeed, the western boundary of this

330 shallower Moho segment coincides with the line of earthquakes (inset in Figure 1) marking the

331 apparently high strain Hazara-Nanga Parbat syntaxes which may be a fault or flexure. However,

332 the eastern boundary of this shallow Moho segment, crossing the rupture zone of the 1905

333 earthquake, which is highlighted by a cluster of moderate and small earthquake ruptures, has no

334 earthquake signatures further towards the Main Mantle Thrust. In any case, these bounding arc-

335 normals, would be expected to accommodate the shallower dipping Indian plate between them

336 through warped shear zones, which has significant pointers to model possible rupture scenarios

337 for quantifying seismic hazard in the region. Notably, the inferred shallow dip of the Kashmir

338 Himalaya Moho, shown by this work, clearly explains the wider interseismic locked zone

339 observed by Schiffman et al. (2013).

\section{Conclusion}

340 In conclusion, we summarize the following salient features of the crust beneath the NW

341 Himalaya and adjoining regions. Firstly, dispersion maps clearly mark the low velocity enclaves

342 of western Tarim, Tadjik and the Himalayan foreland basins, showing strong correlation (-0.76

343 to -0.99) with the sediment thickness map of Laske and Masters (1997). Shallower dispersion

344 maps $(10-20 \mathrm{sec})$ also delineate the high velocity southeastern margin of the Hindu Kush $\left(\mathrm{V}_{\mathrm{Rg}}\right.$

$345 \sim 3.3 \mathrm{~km} / \mathrm{s})$ extending to the slightly lower velocity northwestern Himalaya $(\sim 3.1-3.2 \mathrm{~km} / \mathrm{s})$. On

346 dispersion maps higher than $30 \mathrm{sec}$ Tibet and northeastern regions are marked by low ( 2.7-3.0

$347 \mathrm{~km} / \mathrm{s}$ ) velocities, apparently representing the thicker crust underneath.

348 Secondly, the inverted shear wave velocity maps clearly demarcate the shallower structures

349 which have strong geomorphic signatures. For example, at $10 \mathrm{~km}$, high shear velocities $(\sim 3.4$

$350 \mathrm{~km} / \mathrm{s}$ ) mark out the Hindu Kush subduction zone, the Pamirs and the northwestern Himalaya, 
351 while low velocities mark the sedimentary basins of Tadjik, western Tarim, and Himalayan 352 foreland basin $(\sim 3.1 \mathrm{~km} / \mathrm{s})$. The high velocities correspond to surface location of high grade 353 crystallines in the Nanga Parbat, gneiss domes in the Pamirs, the obducted Tethys ocean crust in 354 the Hind Kush, and subduction of the Neo-Tethyan oceanic crust beneath the Eurasian plate in 355 Ladakh. At $30 \mathrm{~km}$ the entire northwestern Himalaya and Hindu Kush is characterized by low 356 velocities $(\sim 3.2 \mathrm{~km} / \mathrm{s})$ except for the Pamir $(\sim 3.7 \mathrm{~km} / \mathrm{s})$; such layer(s) have also been reported for 357 other regions of the Himalaya (e.g. Guo et al. 2009; Gilligan and Priestlely 2018). Existence tests 358 for this pervasive layer were done by intensive forward modeling all of which required its 359 existence to fit the data. The deeper $(40-60 \mathrm{~km})$ high velocity signature beneath Nanga Parbat, 360 reflects the existence of the wedge of Indian plate Proterozoics and crystallines detached from 361 the underthrusting Indian plate and stacked up by the southward advance of Tibet over the Indian 362 plate.

363 Finally, we estimate posterior Moho depths beneath the region. The most notable feature 364 reported here is the along strike shallowing of Moho depths beneath the Kashmir Himalaya 365 which beneath the Indus suture zone is found to be $\sim 10 \mathrm{~km}$ shallower compared with its depth 366 beneath arc-normals both east and west of the Kashmir basin, and explains the wider interseismic 367 locking zone reported by Schiffman et al (2013), Jade et al. (2020). Further, this segment is 368 clearly bounded by arc-normals that pass through the rupture zones of the 1905 Kangra and the 3692005 Kashmir earthquakes which define the current epoch seismic gap that has not been ruptured 370 by even a moderate earthquake since 1555 . Results of this study fill the gap left by earlier ones 371 and shed new light on the finer structure of this complex region. Availability of the shear wave 372 velocity database, illuminated the above discussed features, and is further expected to prove 
373 helpful in designing experiments to address the many problems of the region e.g. nature of the

374 Moho upwarp in NW Himalaya, quantification of the hazard.

\section{Acknowledgments}

This study was supported by the project GAP-1010 of the Ministry of Earth Sciences,Government of India. We gratefully acknowledge the logistics support provided by Professor Talat Ahmed, Rakesh Chandra and Shakil Romshoo of the University of Kashmir in the installation of seismic stations at various sites in Kashmir Himalaya. We thank Satish Maurya for providing the velocity models from Maurya et al. (2016). RM would like to thank Ashish for deployment of the instruments in the field and Gokul Saha for essential inputs during initial stages of this work. Availability of the data freely shared by the various national and international agencies, the NCS, IRIS, GEOFON and the RESIF, is deeply appreciated. Figures were generated using the Generic Mapping Tools (Wessel et al., 2013) and the S-plot/NA-plot routines of Sambridge (1999a,b). Topography data were taken from Amante and Eakins, (2009) (January, 2017). Data queries shall be addressed to IAP (parvez@csir4pi.in).

\section{Author Contributions}

IAP and VKG designed the Kashmir broadband seismic experiment. RRM executed the installation and servicing of the broadband sites, with support from IAP, and performed all the data analysis. RRM produced the first draft which was developed to its present form by contributions made by all the authors. 


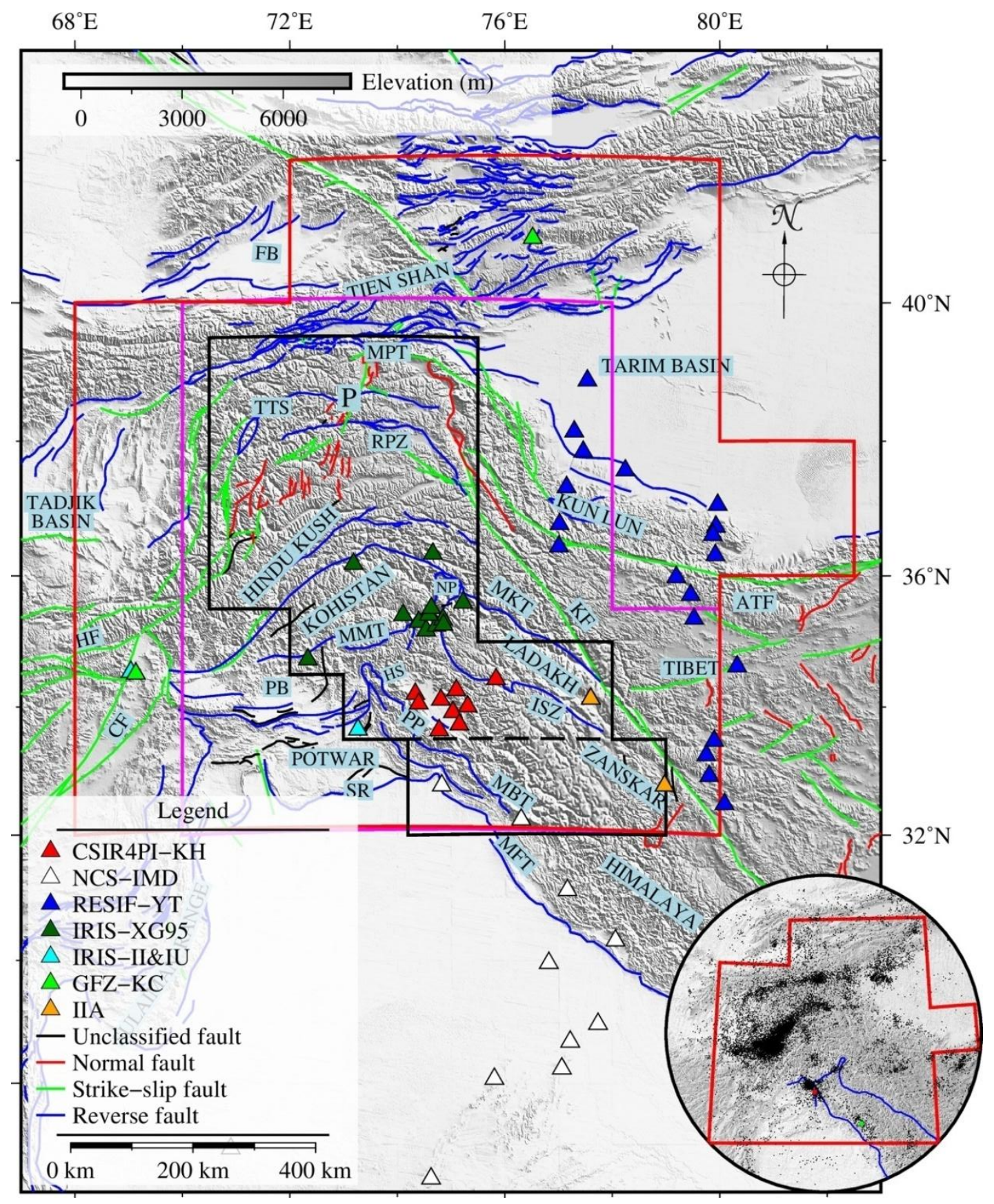

375 Figure 1, Shows the location of broadband stations used in this study. Red triangles denoted by

376 CSIR4PI-KH (see legend) are Kashmir Himalaya broadband stations operated since June 2013

377 which contribute $\sim 50 \%$ of the data used in this study (Figure A1). Remaining data are from the 
378 stations operated by the Indian National Centre for Seismology (NCS), the Incorporated 379 Research Institutions for Seismology (IRIS), the GEOFON stations of German Research Centre 380 for Geosciences (GFZ) and the French Seismologic and Geodetic Network (RESIF). Fault 381 locations were taken from the Central-Asia Fault Database (Mohajder et al. 2016) and Yin (2006) 382 with major tectonic blocks designated after Searle et al. (2001). The Karakoram Fault is denoted 383 by KF, the Main Karakorum Thrust by MKT, and the Indus-Tsangpo Suture by ISZ in Ladakh 384 and the Main Mantle Thrust (MMT) further westward. Other abbreviations are MFT: Main 385 Frontal Thrust, MBT: Main Boundary Thrust, PP: Pir Panjal range SW of the Kashmir basin, 386 ATF: AltynTagh Fault, SR: Salt Range, HS: Hazara Syntaxis, NP: Nanga Parbat syntaxis, CF: 387 Chaman Fault, HF: Heart Fault. The Pamirs (denoted by P) lying between the north bounding 388 Main Pamir Thrust (MPT) and Hindu Kush are divided into 3 main segments by the Tanyamas 389 Thrust system (TTS) and the Rushan-Pshart suture zone (RPZ) (Schurr et al. 2014). Topographic 390 data were taken from ETOPO1 (Amante and Eakins, 2009). The red boundary demarcates the 391 well resolved region at potential resolution of $1^{\circ}$ up till the $40 \mathrm{sec}$ period and the magenta one up 392 till $60 \mathrm{sec}$. The region delineated by the black is well resolved at potential resolution of $0.5^{\circ}$ till $39360 \mathrm{sec}$ period except for the small region below the dashed line which is well resolved at 0.5 394 resolution only up to 40 seconds. Inset shows the study region overlaid with $19422 \mathrm{M} \geq 4$ 395 earthquake epicenters obtained from the International Seismological Centre (ISC,2016) reviewed 396 catalog for the period 1961-2016. Blue lines denote the MMT/ISZ and the MBT. The red and 397 green circles respectively represent epicenters of $2005\left(\mathrm{M}_{\mathrm{w}} 7.6\right)$ Kashmir and 1905 Kangra $398\left(\mathbf{M}_{\mathrm{w}} 7.8\right.$; Ambraseys and Douglas, 2004) earthquakes. Note the line of earthquakes marking the 399 Hazara-Nanga Parbat syntaxes (for details see section 4.2). 

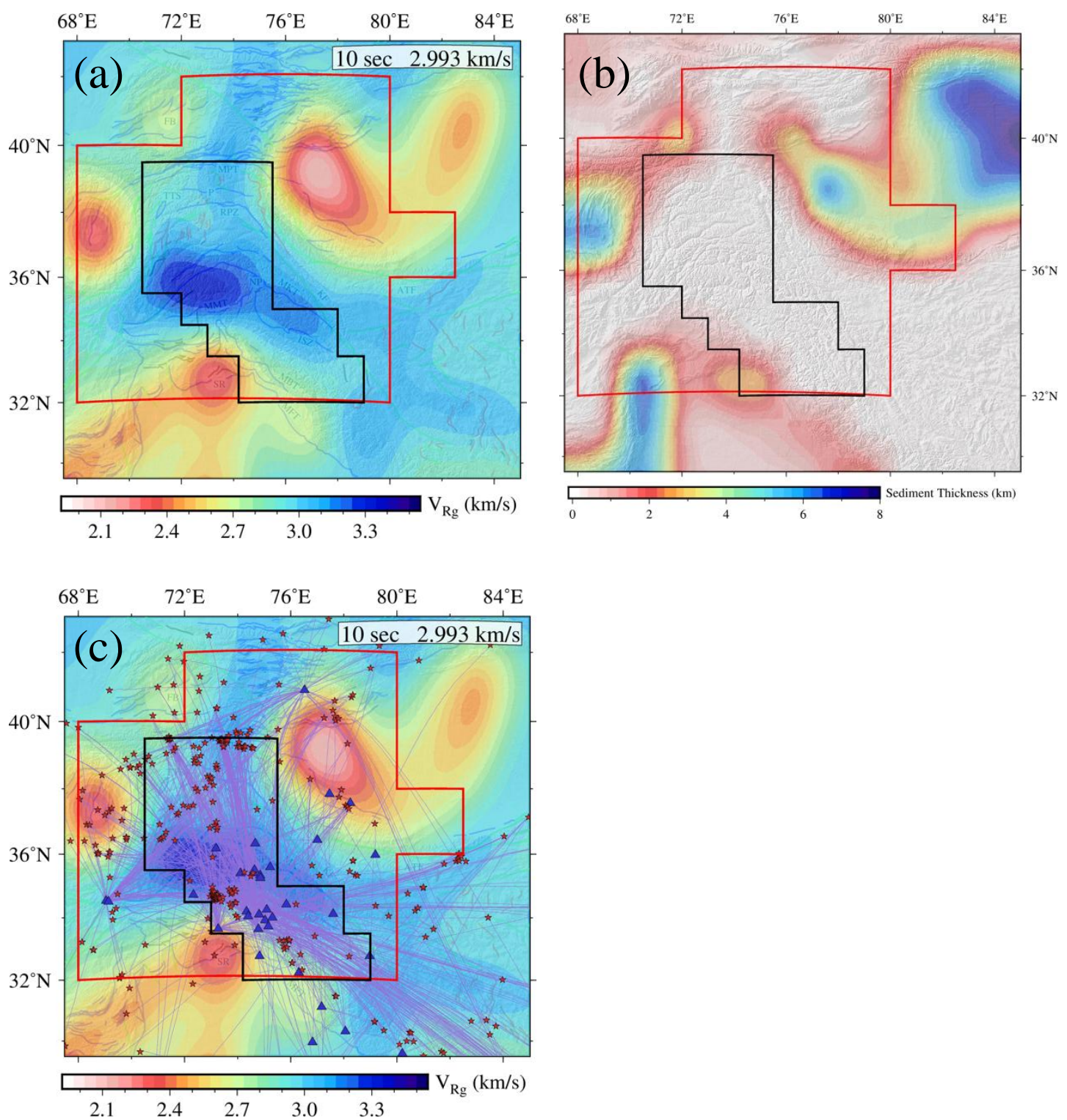

400 Figure 2, a) shows the $10 \mathrm{sec}$ dispersion map of the region and b) the sediment thickness map of 401 Laske and Masters (1997), with boundaries identical to those in Figure 1. The background 402 velocity at this period $(2.993 \mathrm{~km} / \mathrm{s})$ is shown on the top right of (a). Note the low velocity 403 enclaves corresponding to the prominent sedimentary basins: the Tarim, the Tadjik, the Fergana 404 as well as the Potwar and the Himalayan foreland basin to its southeast; (c) shows great-circle 405 paths between sources (stars) and receivers (triangles) for the 10 second period superimposed on 
406 the group velocity map. Note the high density path coverage over the well resolved region (black 407 boundary) which covers the NW Himalaya, the Hindu Kush and the Pamir. The larger region 408 marked by the red boundary is well resolved at lesser resolution. High velocity signature of the 409 Aravalli craton can also be seen at this period (Figure A2) even as it lies far outside the red 410 boundary, testifying to the robustness of dispersion maps. 

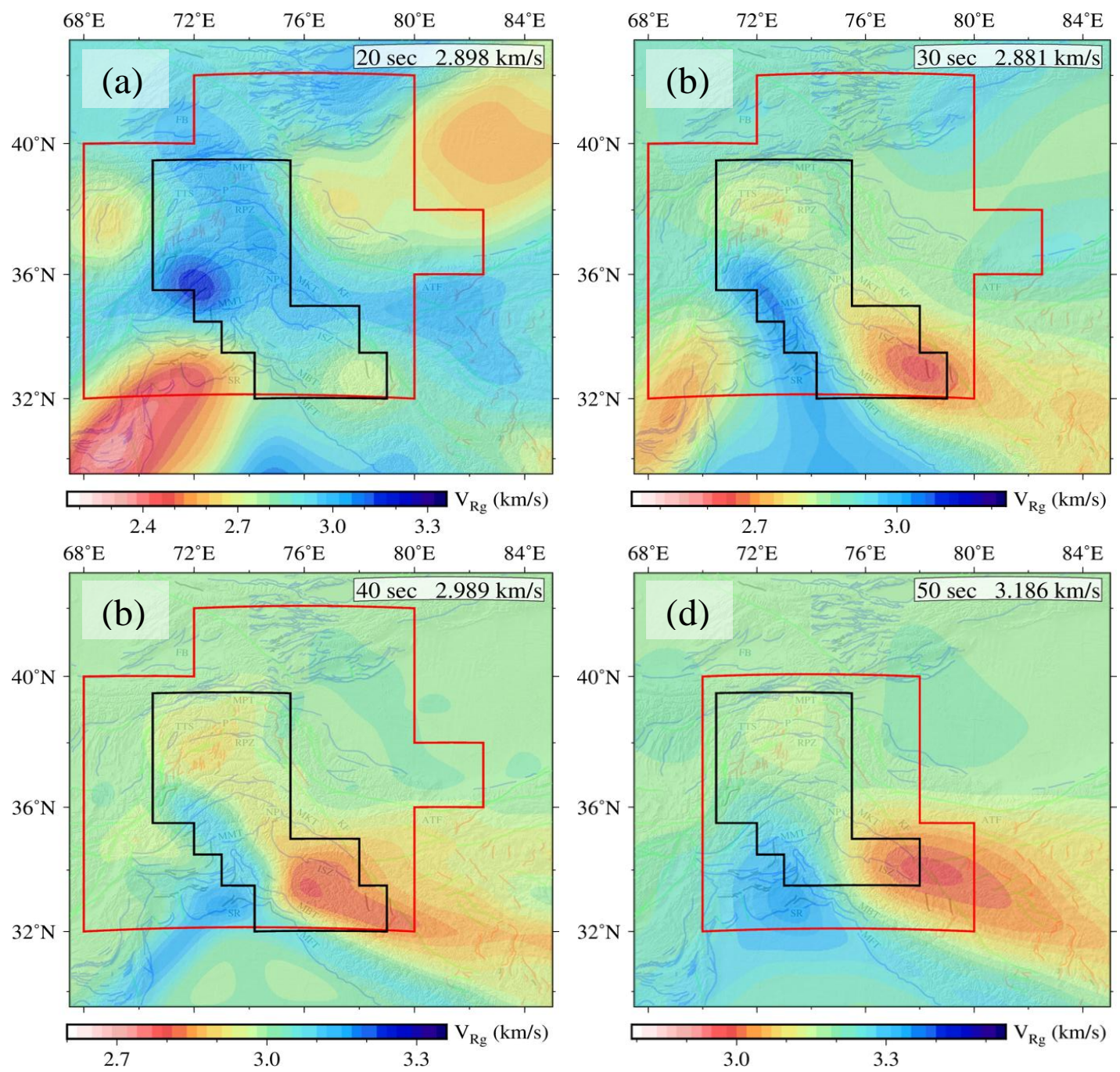

411 Figure 3 shows fundamental mode Rayleigh wavegroup velocity maps for periods of 20, 30, 40,

412 and $50 \mathrm{sec}$, with background velocities at each period shown on the top right. Low velocity

413 signatures of the Tadjik, the northern Indus and the western Tarim basins are seen even on the 20

414 sec period map. The prominent high velocity cores of the Hindu Kush and Nanga Parbat persists

415 up to $\sim 30 \mathrm{sec}$ period, merging with that representing the Indian plate at higher periods. Low

416 velocities beneath southwestern Tibet, Zanskar and the Ladakh Himalaya, for periods higher than

$41720 \mathrm{~s}$, reflect the thicker crust underneath. The regions within the various colored polygons have

418 resolutions as stated in the caption of Figure 1. 


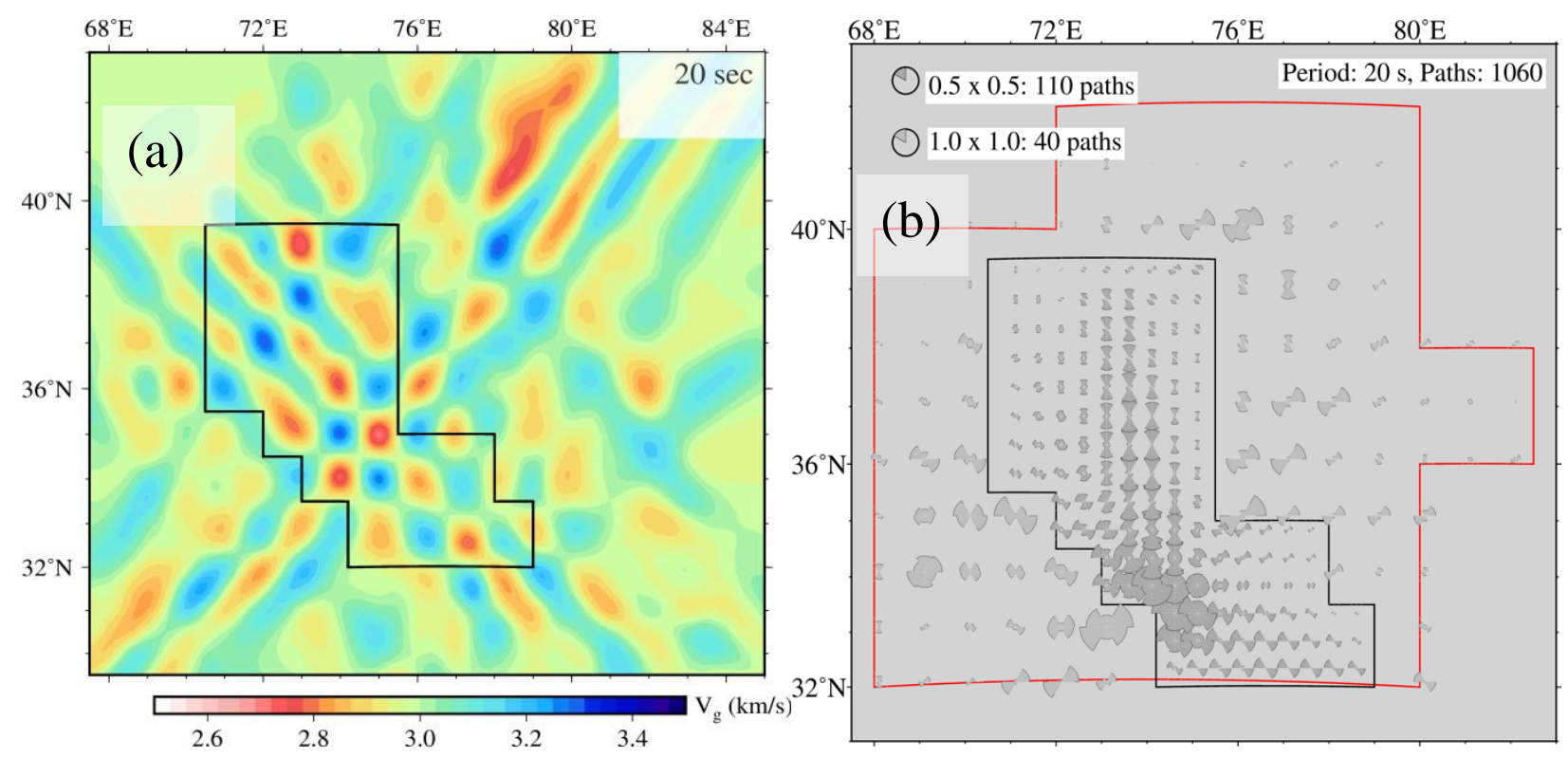

419 Figure 4, (a) shows checkerboard solution model for $0.5^{\circ} \times 0.5^{\circ}$ anomalies with the maximum 420 available raypath coverage at the $20 \mathrm{~s}$ period. Note that NW Himalaya and the adjoining regions 421 of Kohistan, Hindu Kush, and Pamir are well resolved (b) shows azimuthal variation and path 422 density of rays at $0.5^{\circ} \times 0.5^{\circ}$ grid nodes for the region bounded by the black polygon and at $1.0^{\circ}$ $423 \times 1.0^{\circ}$ for the surrounding area bounded by the red polygon. Scales representing number of paths 424 for the two regions are stated on the left hand top corner. 

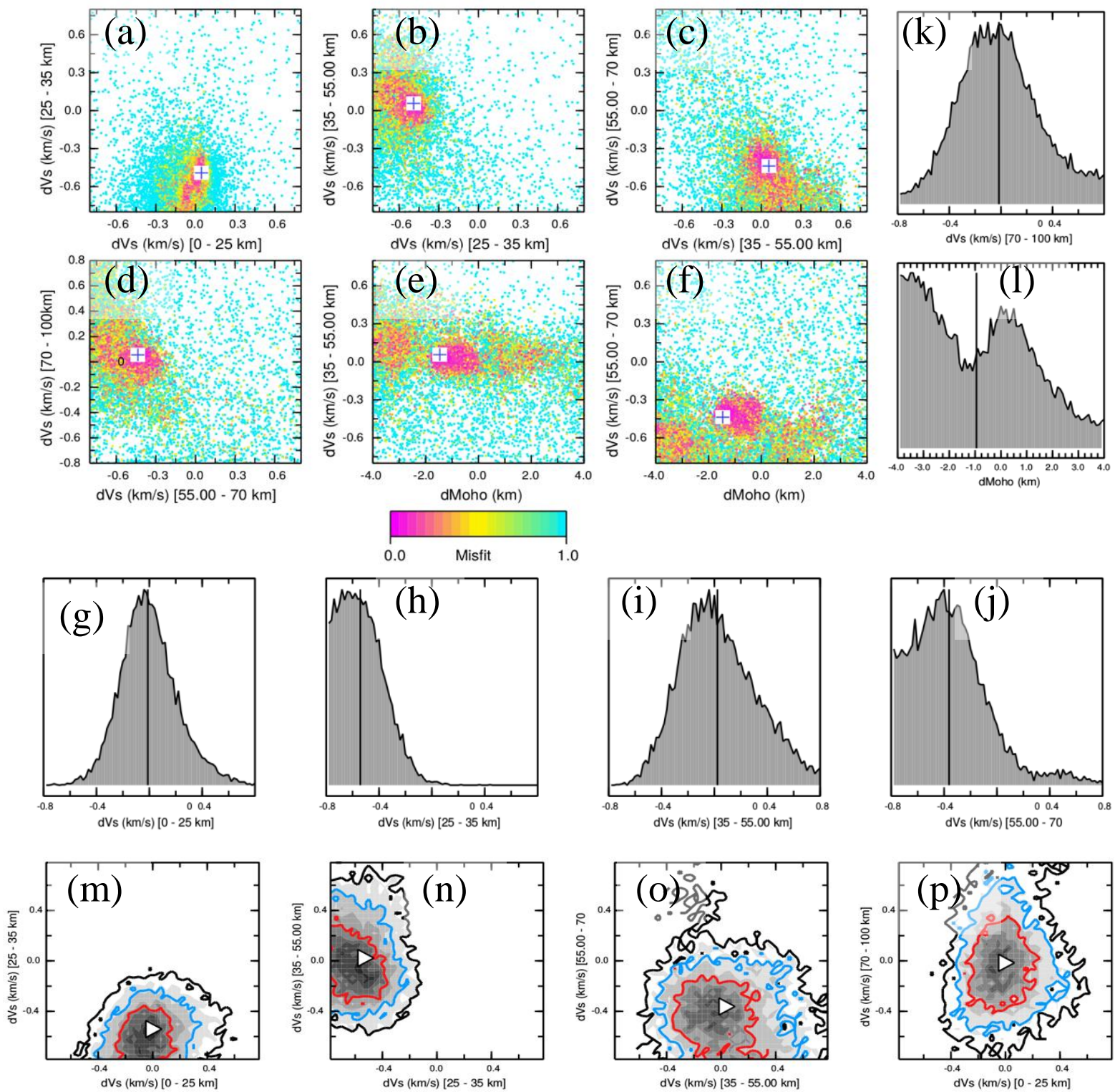

425 Figure 5(a-f) shows the models (32200) generated for the site 34.5N, 74.5E using NA sampling,

426 by perturbing the a-priori model for the same site taken from Maurya et al. (2016). The dense

427 regions with ' + ' sign show the models with least misfit. The a-priori Moho depth beneath this

428 site was $55 \mathrm{~km}$ at which Vs crosses the $4.4 \mathrm{~km} / \mathrm{s}$ value. Note the close-fitting convergence regions

429 upto Moho (a-c), even as the convergence of Vs is not global for the upper mantle. (g-l) shows

430 the 1D Posterior Probability Distribution Functions (PPDF) for Vs from 0-100 km and the Moho

431 depth $(55 \mathrm{~km})$, the $\mathrm{x}$-axis denoting allowed deviations of the parameter $( \pm 0.8 \mathrm{~km} / \mathrm{s}$ for Vs and \pm 4 
$432 \mathrm{~km}$ for the Moho) and the $\mathrm{y}$-axis, its probability. Note that Vs is well resolved till $100 \mathrm{~km}(\mathrm{~g}-\mathrm{k})$, 433 while the Moho depth is less well resolved (1). The black line denotes the posterior mean of the 434 parameter e.g. $\left[\mathrm{V}_{\mathrm{s}(55-70)^{-}}\right.$0.39] km/s for the 55-70 km layer shown in (j)]. (m-p) showthe 2-D 435 PPDF's for Vs up till $100 \mathrm{~km}$, where 90\% confidence intervals are shown in red, and the 436 triangles denote its posterior mean values. 


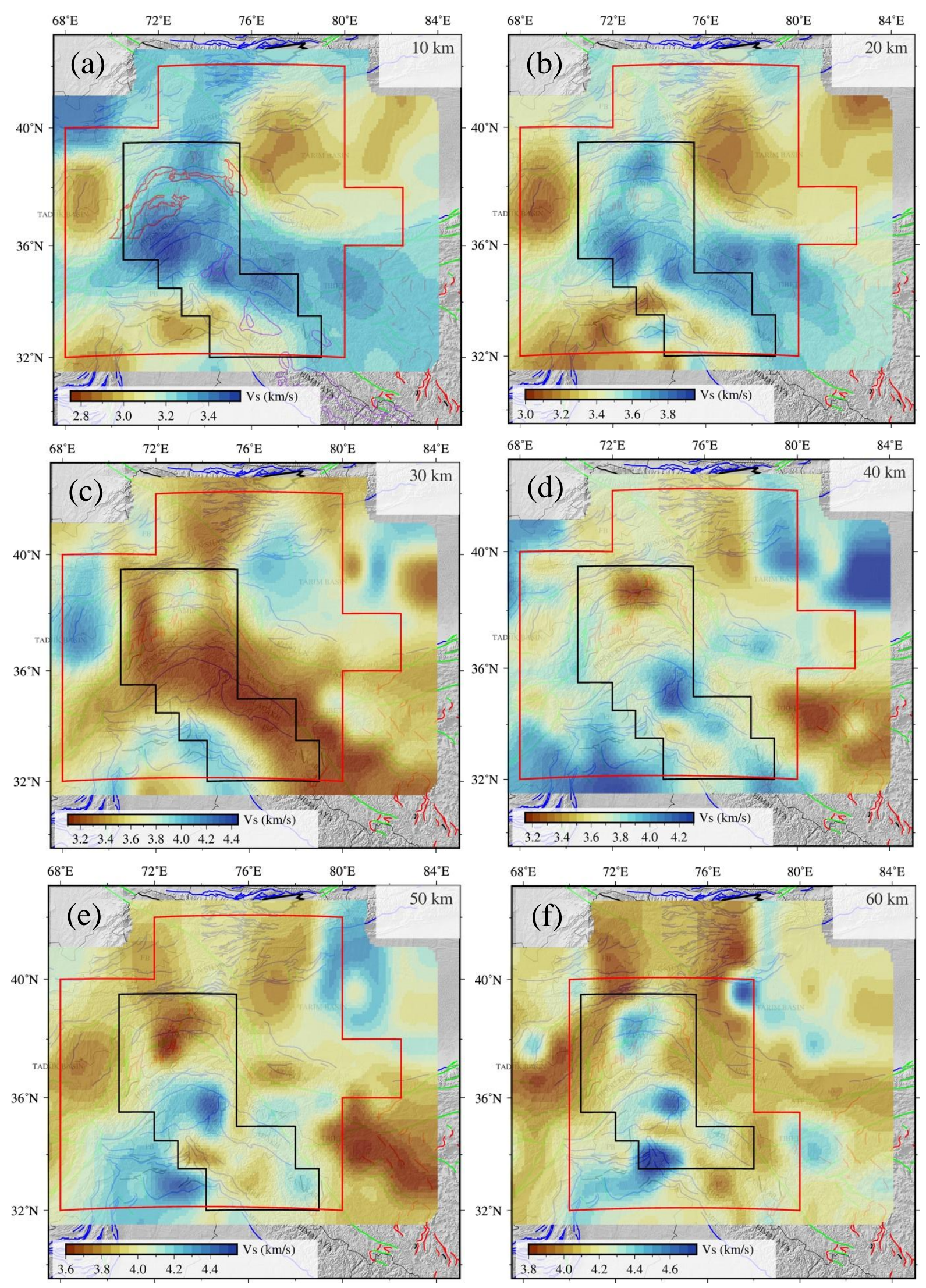



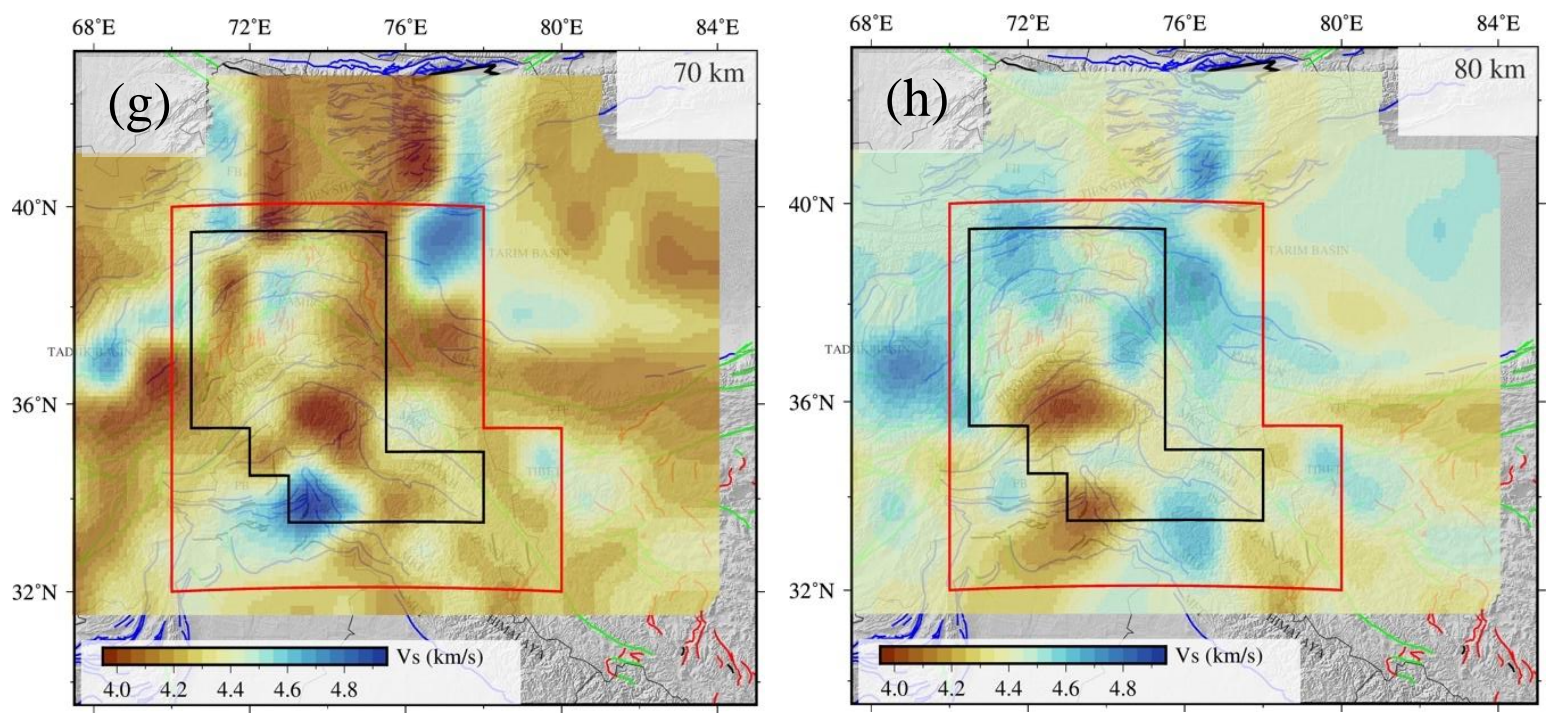

445 Figure 6 (a-h) shows slices of shear wave velocities in the region between 10-80 km, at depth 446 intervals of $10 \mathrm{~km}$. Note the high velocity enclaves beneath the Pamir, the Nanga Parbat and the 447 Ladakh Himalaya at $10 \mathrm{~km}$ depth, becoming stronger at $20 \mathrm{~km}$ depth. These correlate well with 448 surface exposures of the gneiss domes in Pamir and with the crystalline complexes beneath the 449 Nanga Parbat (drawn in a). Also note the low velocity layer beneath the Himalaya, Tibet, Hindu 450 Kush at depth of $30 \mathrm{~km}$ (c), with Pamir at a marginally higher velocity of $\sim 3.7 \mathrm{~km} / \mathrm{s}$. For details 451 see sections 3 and 4. Posterior error map for each slice (a-h) is plotted in Figure A3. The regions 452 within the various colored polygons have resolutions as stated in the caption of Figure 1. 


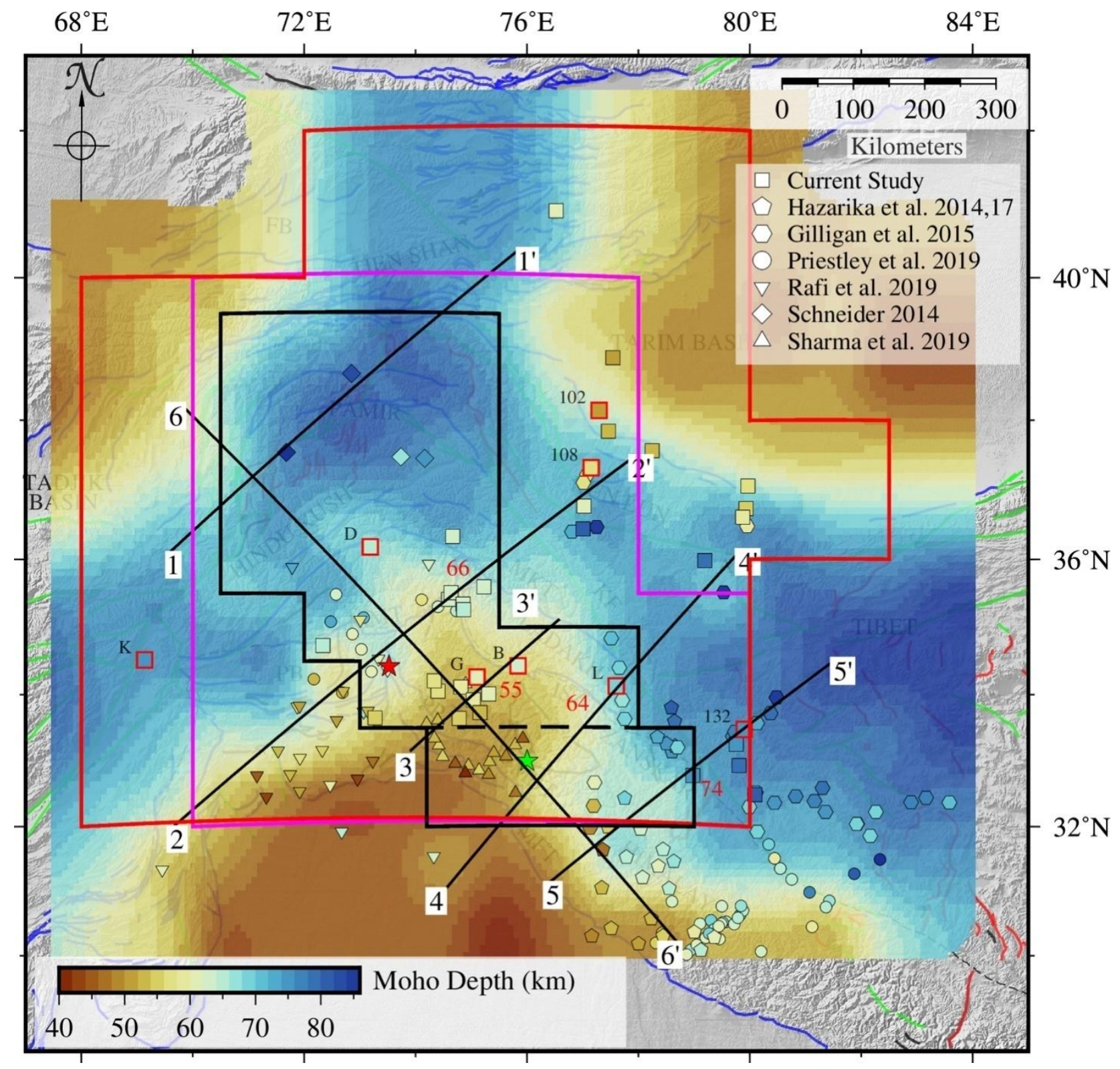

453 Figure 7 shows posterior Moho depth estimates for the region. The a priori Moho was chosen as

454 the depth where Vs crosses the iconic value of $4.4 \mathrm{~km} / \mathrm{s}$. The average Moho depth in the region is

455 found to be $\sim 70 \mathrm{~km}$, with higher depths beneath Tibet and the Pamir and shallow beneath the

456 Tarim, Tadjik and Fergana basins, as well as theHimalayan foreland basin. Moho depths

457 calculated from joint inversion of RFs and surface wave dispersion data at 38 sites are shown as

458 squares on this map using the same color code as those used for the NA inversions (see legend). 
459 All authors mentioned in the legend have used either RF inversion or joint inversion of RF and 460 surface wave data to constraint the Moho depths underneath, except Schneider (2014) who used 461 a slant-stacking method. The Moho is found to be distinctly shallower by as much as $10 \mathrm{~km}$ in 462 the region bounded by arc-normals that pass through the epicenters of the 1905 Kangra and 2005 463 Kashmir earthquakes marked as green and red stars respectively (ISC, 2016; Ambrayses and 464 Doughlas, 2004). Estimated Moho depths within the black region are largely consistent with 465 published results. A notable feature of this map is the continuance of deeper Moho further 466 northeast of the Kunlun-AltynTagh fault compared with estimates reported earlier (e.g. 467 Wittlinger et al., 2004). Velocity structure beneath 8 of the 38 sites marked with red boundary 468 and denoted by the first letter of their station code (full name if numeric) is shown in Figure 8. 469 The posterior shear-wave velocity structure with depth along 5 NE-SW profiles, labeledas1-1' to $4705-5$ ' are shown in Figure 9, along with a NW-SE profile 6-6'. The regions within the various 471 colored polygons have resolutions as stated in the caption of Figure 1. 
(A)
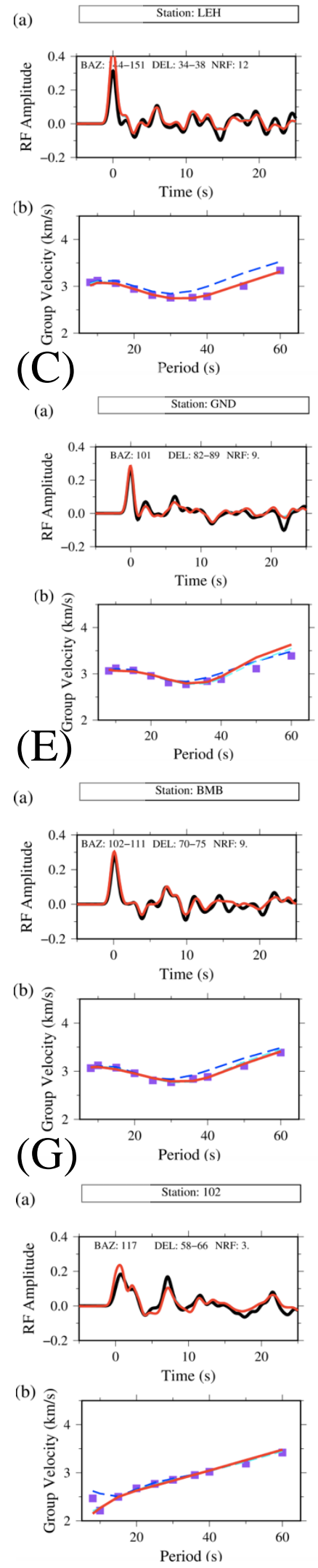

(B)
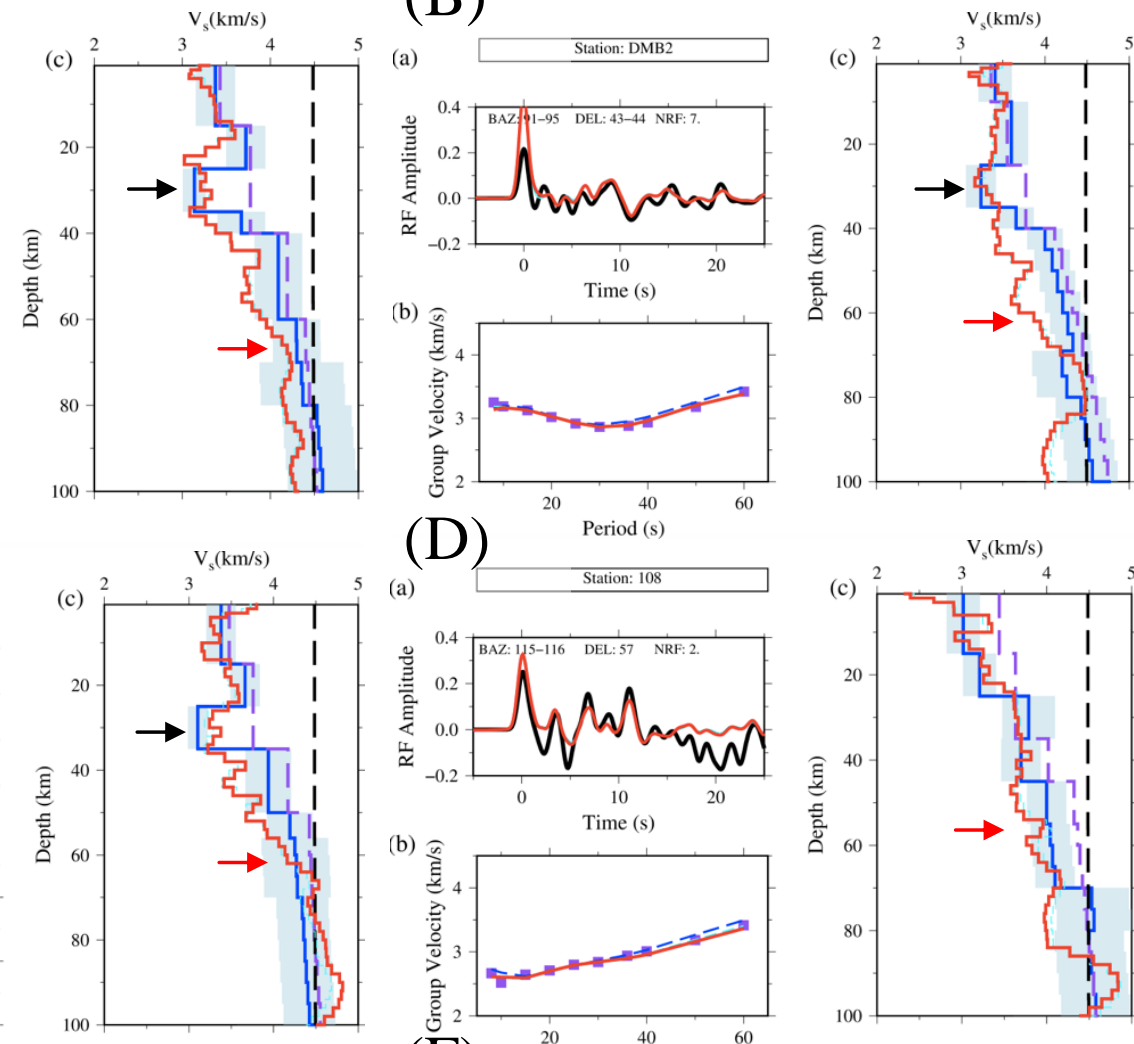

(D) Period (s)
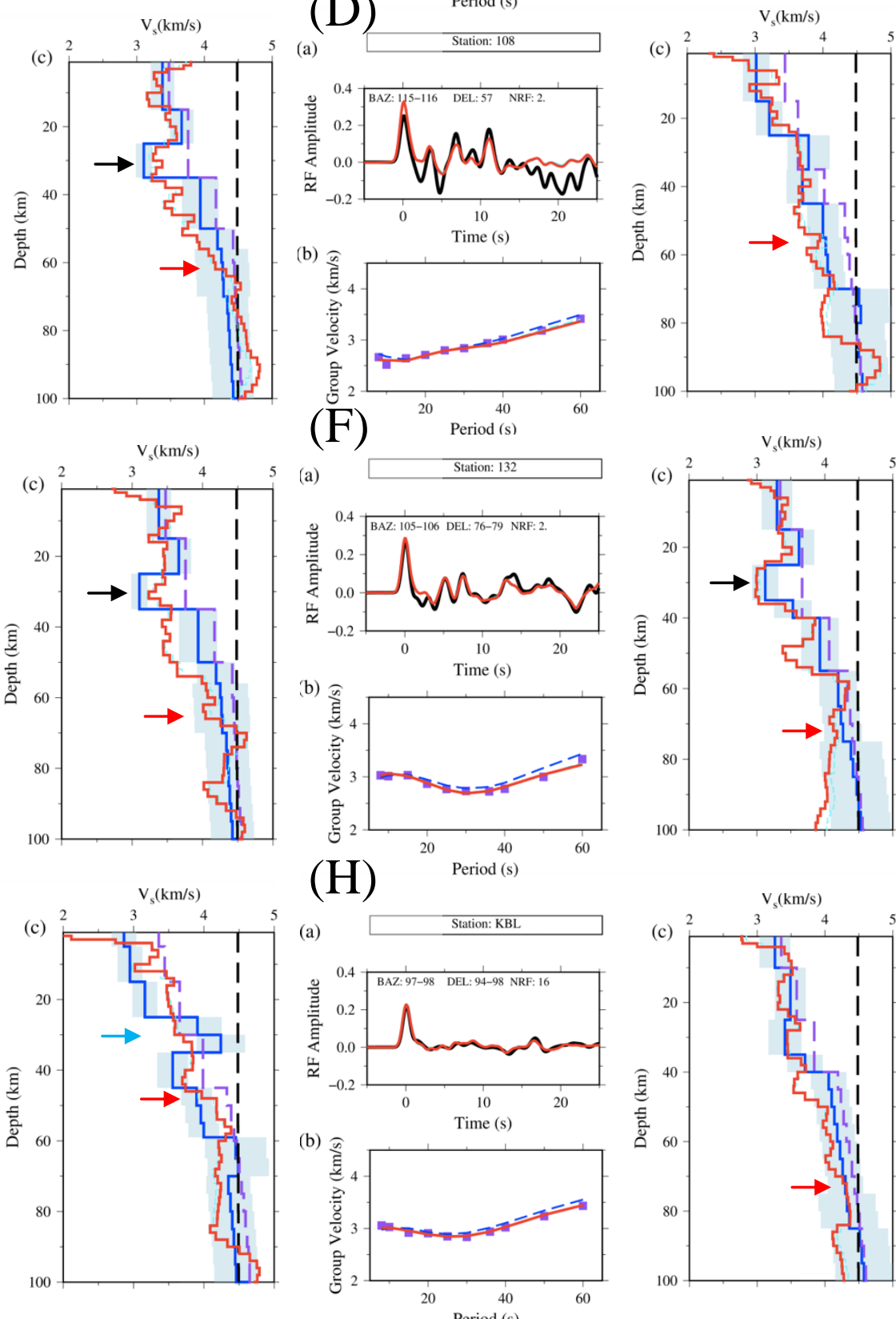
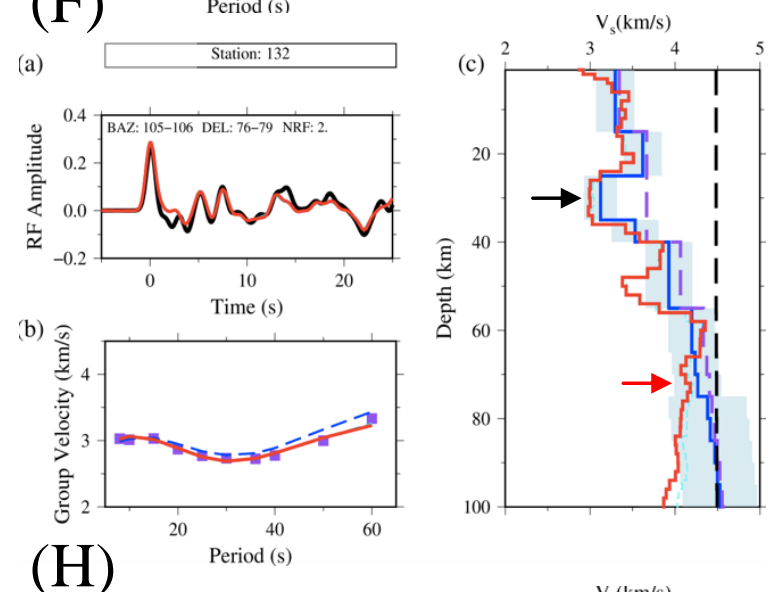

(H)
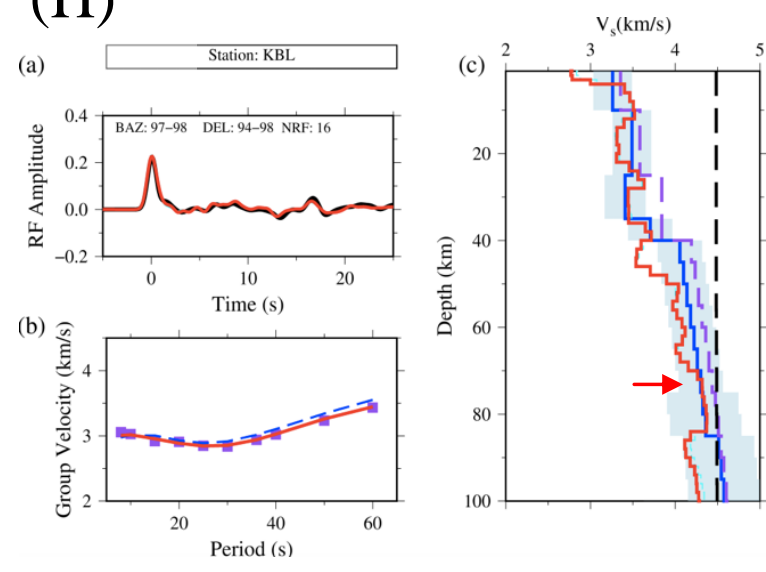
472 Figure 8 shows the posterior shear wave velocity models (blue lines), overlaid on models 473 obtained from joint inversion of receiver function and weakly weighted (10 and 20\%) surface 474 wave dispersion measurements (red \& cyan lines) for 8 different sites (A-H). Locations of sites 475 are shown in Figure 7 as squares within the red boundary. At each site, the station name is 476 plotted on top of the calculated (black) and recovered receiver functions (red), plotted in (a). 477 Observed (purple) and predicted (blue, red and cyan) dispersion curves are plotted in (b). The a478 priori Vs model from Maurya et al. (2016) is plotted as a dashed purple line in (c) along with the 479 posterior Vs model (blue) where the error bounds on Vs (light blue) represent the mean error of 480 the ensemble of best models. The initial model for joint inversion is shown by the black dashed 481 line (Vs $\sim 4.48 \mathrm{~km} / \mathrm{s}$ ) and the corresponding final model, by red and cyan lines, respectively 482 representing $10 \%$ and $20 \%$ weightage of surface waves dispersion data in joint inversion. Note 483 the appearance of the pervasive low velocity layer at depths of $\sim 25-35 \mathrm{~km}$, except at the stations 484 102, 108 and KBL.Moho depths are denoted by red arrows and the intra crustal low velocity 485 layer at $\sim 30 \mathrm{~km}$, observed at few stations (B,C,E,F), by black arrows. A high velocity layer 486 observed at $\sim 30 \mathrm{~km}$ beneath the Tarim basin $(\mathrm{G})$ is marked by a blue arrow. 
(a)

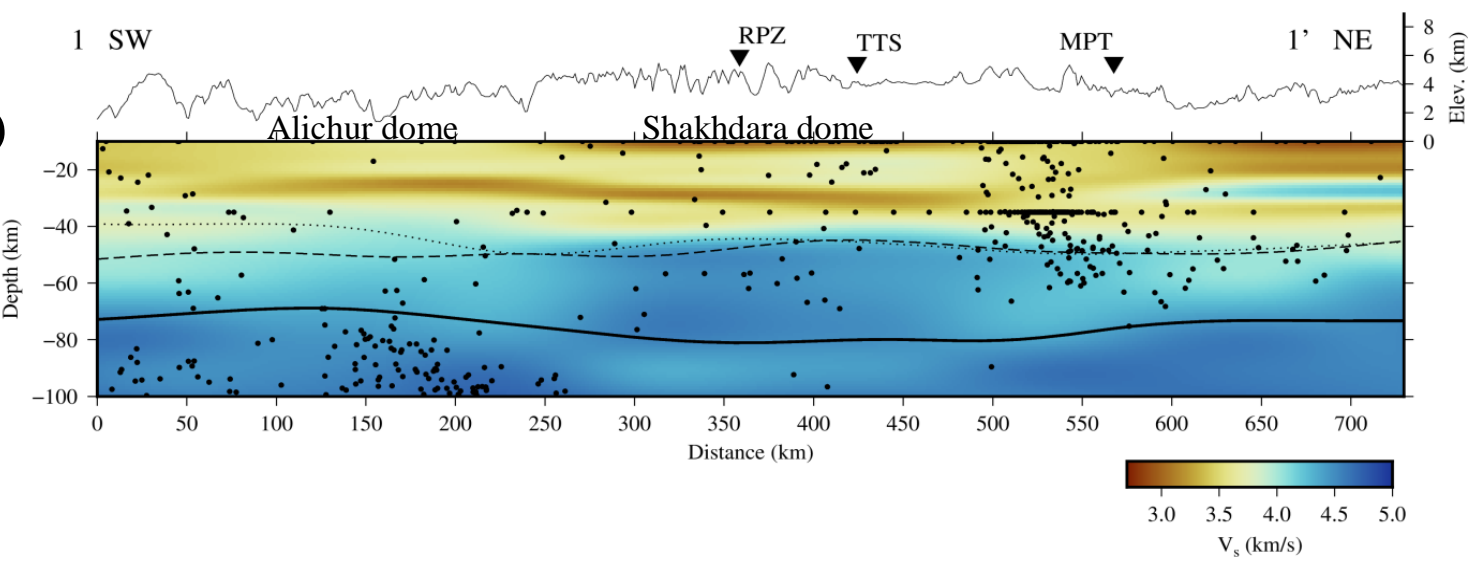

(b)

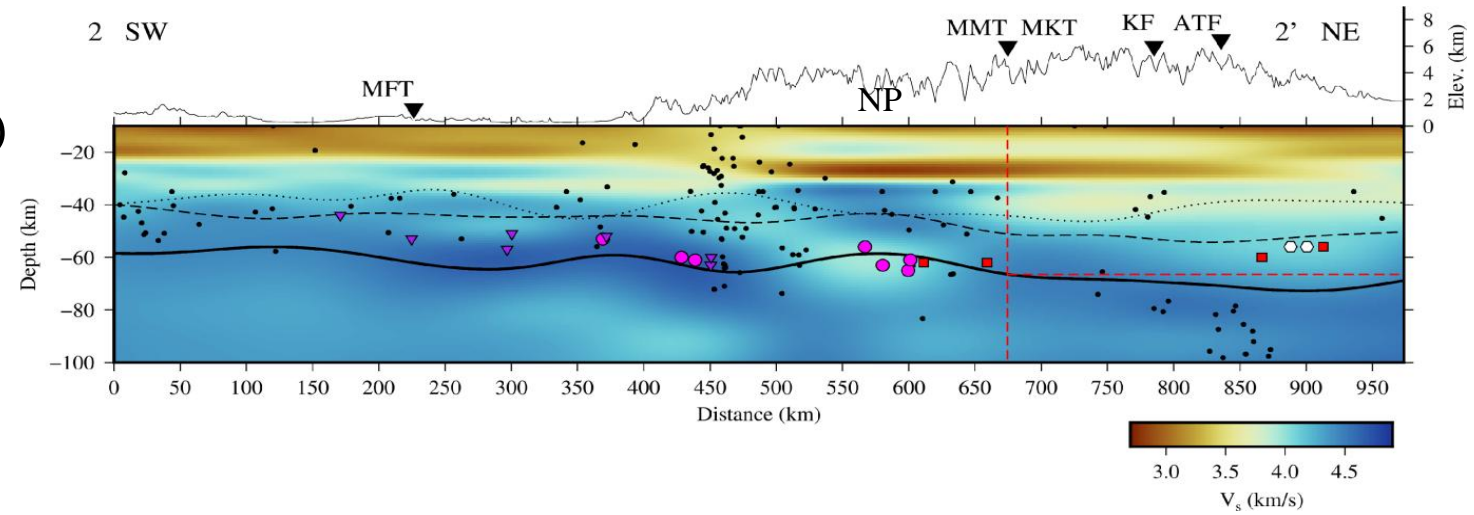

$3 \mathrm{SW}$

(c)

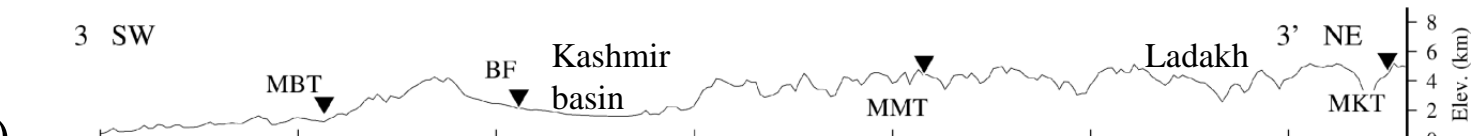

(d)
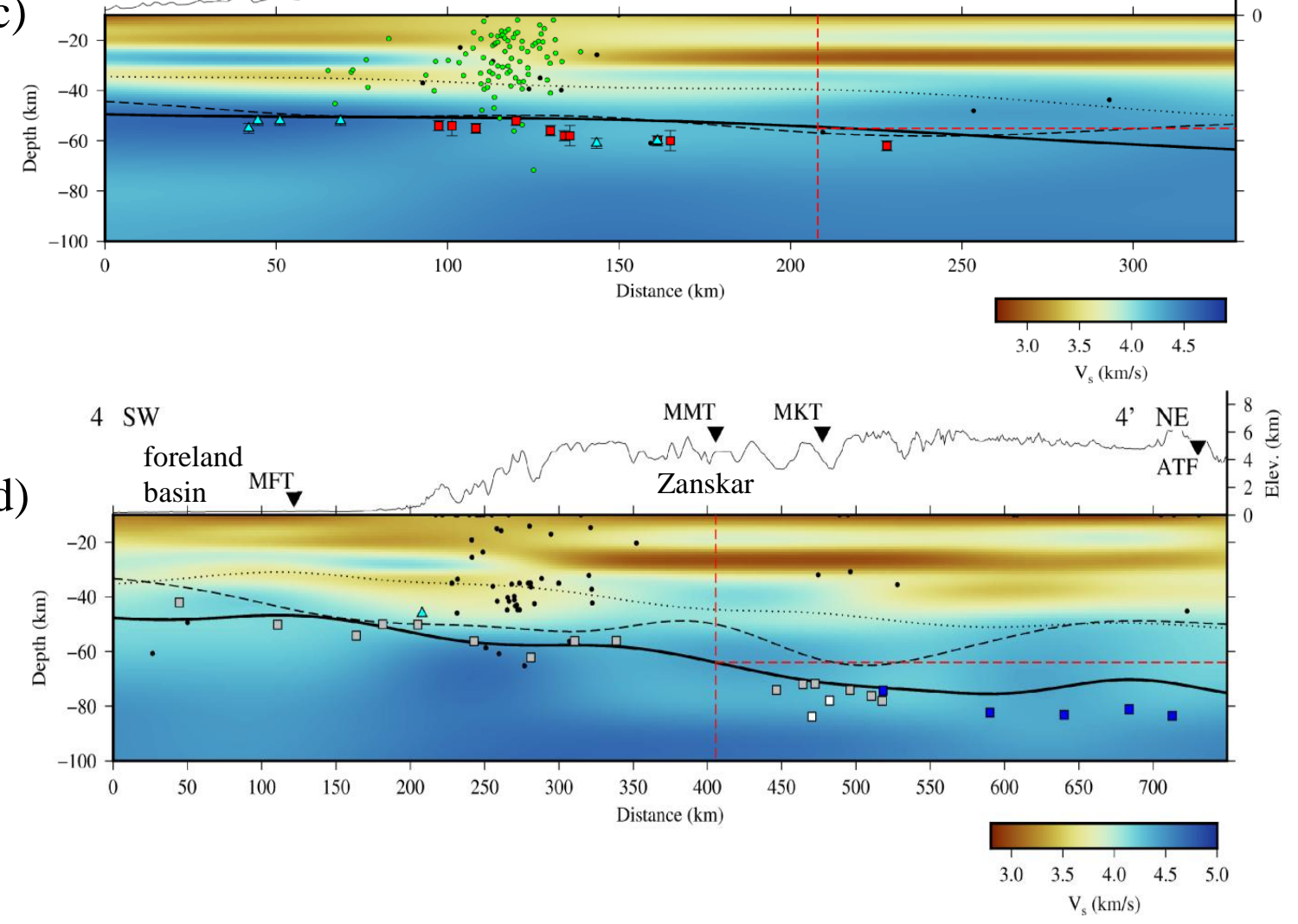

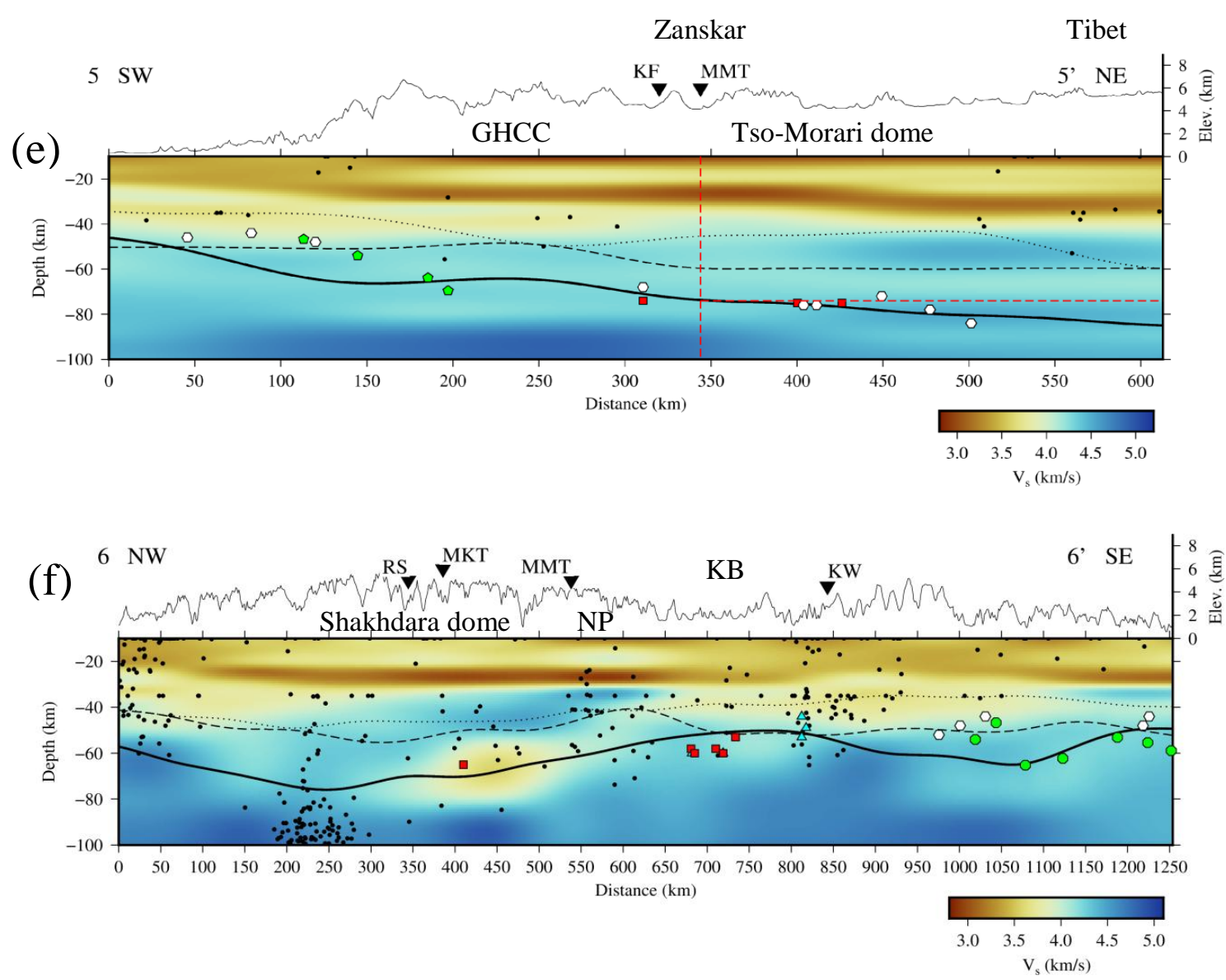

Figure 9, shows the posterior Vs cross-sections and Moho depths along 5 NE-SW (a-e) and 1 NW-SE profile (f), marked by dotted, dashed and solid black lines, respectively estimated from 3 different initial a-priori models identifying the Moho surface with velocities of 4.0, 4.2 and 4.4 $\mathrm{km} / \mathrm{s}$. Moho surfaces for depths marked on each profile are values constrained by inversions of receiver functions (Figure 7), some jointly with surface wave dispersion data, and no farther than $35 \mathrm{~km}$ from it to ensure consistency with the lateral resolution of receiver function. Profile (a)which crosses 2 of the 5 gneiss domes in Pamir including the largest Shakhdara dome are clearly identified by their high velocity signatures up to $\sim 20 \mathrm{~km}$. Similarly, profile (b) which 
extends from the foreland basin in the southwest to Nanga Parbat (NP) also brings out the high velocity character of the latter. Note also that Moho depth beneath the MMT north of the NP is $66.5 \mathrm{~km}$, marked by a dashed red line. Profiles (c) and (d) shows Moho depths and Vs along two profiles [Mir et al. unpublished (c); Rai et al. 2006 (d)], indicating that Moho depths beneath the MMT southeastwards are $55 \mathrm{~km}$ and $64 \mathrm{~km}$ respectively.The easternmost arc-normal profile (e) passing through Shimla and the Ladakh Himalaya, shows shallow high $\mathrm{V}_{\mathrm{s}}$ velocities corresponding to the surface location of the Greater Himalayan Crystalline complexes (GHCC) and the Tso-Morari gneiss dome. The corresponding Moho depth beneath the MMT is $\sim 74 \mathrm{~km}$, confirming that the Moho is shallower by $\sim 10 \mathrm{~km}$ beneath the NW Himalaya. The NW-SE profile (f) passes from Pamir to Kishtwar (KW), through Hindu-Kushand the Kashmir Basin (KB), shows that the deepest Moho lies beneath the Pamir and the Hindu Kush. However, the pervasive low velocity layer at $\sim 30 \mathrm{~km}$ found throughout the Himalayas is notably absent beneath the Kashmir basin.

\section{References}

Acton, C.E., Priestley, K., Gaur, V.K., Rai, S.S., 2010. Group velocity tomography of the IndoEurasian collision zone. J. Geophys. Res. 115, B12335.

Amante, C. and B.W. Eakins, 2009. ETOPO1 1 Arc-Minute Global Relief Model: Procedures, Data Sources and Analysis. NOAA Technical Memorandum NESDIS NGDC-24. National Geophysical Data Center, NOAA. doi:10.7289/V5C8276M

Ambraseys, N. and J. Douglas, (2004). Magnitude calibration of north Indian earthquakes. Geophys. J. Int., 159:165-206.

Beyreuther, M., Barsch, R., Krischer, L., Megies, T., Behr, Y., and Wassermann, J. (2010), ObsPy: A Python Toolbox for Seismology, Seis. Res. Lett., 81 (3), 530-533.

Dziewonski, A., Bloch, S. and Landisman, M., 1969. A technique for the analysis of transient seismic signals, Bull. Seism. Soc. Am., 59, 427-444.Laske G. and G. Masters, A Global Digital Map of Sediment Thickness, EOS Trans. AGU, 78, F483, 1997. 
Gilligan, A., Priestley, K. F., Roecker, S. W., Levin, V., Rai, S., (2015). The crustal structure of the western Himalayas and Tibet. J.Geoph. Res.: Solid Earth Earth 120 (5), 3946-3964.

Gilligan, A., and Priestley, K. (2018). Lateral variations in the crustal structure of the IndoEurasian collision zone. Geophy. J. Int., 214(2), 975-989. DOI: $\underline{10.1093 / g j i / g g y 172}$

Goldstein, P., and A. Snoke (2005). SAC Availability for the IRIS Community, Incorporated Research Institutions for Seismology Data Management Center, Electronic Newsletter, available at http://ds.iris.edu/ds/newsletter/vol7/no1/sac- availability- for- the- iris- community/(last accessed January 2013).

Guo, Z., X. Gao, H. Yao, J. Li, and W. Wang (2009), Midcrustal low-velocity layer beneath the central Himalaya and southern Tibet revealed by ambient noise array tomography, Geochem. Geophys. Geosyst., 10, Q05007, doi:10.1029/2009GC002458.

Hazarika D., Sen K., Kumar N. (2014). Characterizing the intracrustal low velocity zone beneath northwest India-Asia collision zone, Geophy. J. Int., 99, 3, 1338-1353, https://doi.org/10.1093/gji/ggu328

Hazarika, D., Wadhawan, M., Paul, A., Kumar, N., Borah, K., 2017. Geometry of the Main Himalayan Thrust and Moho beneath Satluj Valley, northwest Himalaya: Constraints from receiver function analysis. J.Geoph. Res.: Solid Earth 122 (4), 2929-2945.

Herrmann, R.B., 1973. Some aspects of band-pass filtering of surface waves, Bull. seism. Soc. Am., 63, 663-671.

Herrmann, R.B. and Ammon, C.J., 2004. Surface waves, receiver functions and crustal structure, in Computer Programs in Seismology, Version 3.30, Saint Louis University, http://www.eas.slu.edu/People/RBHerrmann/CPS330.html

International Seismological Centre, On-line Bulletin, http://www.isc.ac.uk, Internatl. Seismol. Cent., Thatcham, United Kingdom, 2016. http://doi.org/10.31905/D808B830

Jade, S., Mir, R.R., Vivek, C.G. et al. Crustal deformation rates in Kashmir valley and adjoining regions from continuous GPS measurements from 2008 to 2019. Sci Rep 10, 17927 (2020). https://doi.org/10.1038/s41598-020-74776-5

Kumar S. Magnetic Susceptibility Mapping of Ladakh Granitoids, northwest higher Himalaya: Implication to redox series of felsic magmatism in the subduction environments (2008), Mem. Geol.. Soc. India (BR Arora and R. Sharma, Eds.), 72, 83-102

Laske, G. and Masters, G., 1997. A global digital map of sediment thickness,EOS, Trans. Am. geophys. Un., 78, F483.

Laske, G., Masters., G., Ma, Z. and Pasyanos, M., Update on CRUST1.0 - A 1-degree Global Model of Earth's Crust, Geophys. Res. Abstracts, 15, Abstract EGU2013-2658, 2013. 
Li W., Chen Y., Yuan X.,SchurrB., Mechie J.,OimahmadovI.,and Fu B., (2018) Continental lithospheric subduction and intermediate-depth seismicity: Constraints from S-wave velocity structures in the Pamir and Hindu Kush, Earth Planet. Sci. Lett., 482, 478-489

Maurya, S., J.-P. Montagner, M. R. Kumar, E. Stutzmann, S. Kiselev, G. Burgos, N. P. Rao, and D. Srinagesh (2016), Imaging the lithospheric structure beneath the Indian continent, J. Geophys. Res. Solid Earth, 121, doi:10.1002/2016JB012948.

Mir R. R., Parvez I. A., Gaur V. K., Chandra R., Romshoo S. A., (2017) Crustal structure beneath the Kashmir Basin adjoining the western Himalayan syntaxis. Bull.Seismol. Soc. Am. 107(5):2443-2458

Mitra, S., K. Priestley, V. Gaur, S. Rai, and J. Haines (2006), Variation of Rayleigh wave group velocity dispersion and seismic heterogeneity of the Indian crust and uppermost mantle, Geophys. J. Int., 164(1), 88-98.

Mohadjer, S., Ehlers, T.A., Bendick, R., Stübner, K., Strube, T. (2016) A Quaternary fault database for central Asia, Nat. Hazards Earth Syst. Sci., 16, 529-542, doi:10.5194/nhess-16-5292016.

Okabe, A., Boots B., Sugihara K., Chiu S. N., (2000). Spatial Tessellations: Concepts and Applications of Voronoi Diagrams, 2nd Edition, Wiley, pp. 696

Park, S., and Mackie, R., (1997). Crustal structure at Nanga Parbat, northern Pakistan, from magnetotelluric soundings, Geophy. Res. Lett., 24, 2415-2418.

Priestley K., Ho T., and Mitra S., (2019). The crust structure of the Himalaya: a synthesis, Geological Society, London, Special Publications, 483, https://doi.org/10.1144/SP483-2018-127

Rafi, Z., Priestley, K., Mahmood, N., Gilligan, A., 2019. Crustal structure of the Indus Valley Plain and the Western Himalayan Syntaxis of Pakistan. Geophysical Journal International submitted.

Rai, S.S., Priestley, K., Gaur, V.K., Mitra, S., Singh, M.P. \& Searle, M., 2006. Configuration of the Indian Moho beneath the NW Himalaya and Ladakh, Geophys. Res. Lett., 33, L15308, doi:10.1029/2006GL026076.

Rawlinson, N., Sambridge, M., 2004. Wavefront evolution in strongly heterogeneous layered media using the fast marching method. Geophys. J. Int. 156, 631-647.

Rawlinson, N. and Sambridge M., 2005. The fast marching method: An effective tool for tomographic imaging and tracking multiple phases in complex layered media,Explor. Geophys., $36,341-350$ 
Ritzwoller, M. H., Shapiro, N. M., Barmin, M. P., \&Levshin, A. L., 2002. Global surface wave diffraction tomography, J. Geophys. Res.: Solid Earth, 107(B12)

Sambridge, M., Geophysical Inversion with a Neighbourhood Algorithm -I. Searching a parameter space, Geophys. J. Int., 138 , 479-494, 1999a.

Sambridge, M., Geophysical Inversion with a Neighbourhood Algorithm -II. Appraising the ensemble, Geophys. J. Int., 138 ,727-746, 1999 b.

Schiffman, C., B. S. Bali, W. Szeliga, and R. Bilham (2013). Seismic slip deficit in the Kashmir Himalaya from GPS observations, Geophys. Res. Lett. 40, 5642-5645, doi: 10.1002/2013GL057700.

Schneider, F. (2014), Imaging an Intra-continental Subduction in Central Asia with Teleseismic Receiver Functions. Scientific Technical Report 14/06, GFZ German Research Centre for Geosciences. doi: 10.2312/GFZ.b103-14063

SchneiderD. A., M. A. Edwards, W. S. F. Kidd, M. Asif Khan, L. Seeber, P. K. Zeitler; Tectonics of Nanga Parbat, western Himalaya: Synkinematic plutonism within the doubly vergent shear zones of a crustal-scale pop-up structure. (1999) Geology ; 27 (11): 999-1002

Schurr, B., Ratschbacher, L., Sippl, C., Gloaguen, R., Yuan, X., Mechie, J., 2014. Seismotectonics of the Pamir. Tectonics 33, 1501-1518. http://dx.doi.org/10.1002/ 2014TC003576

Searle, M., Hacker, B. R., and Bilham R., (2001). The Hindu Kush Seismic Zone as a Paradigm for the Creation of Ultrahigh-Pressure Diamond- and Coesite-Bearing Continental Rocks, The Journal of Geology, 109, 143-153

Sharma, S., Mitra, S., Priestley, K., Powali, D., Wanchoo, S., 2019. Crustal structure of the Jammu and Kashmir Himalayas. Geophy. J. Int. submitted.

Wessel, P., W. H. F. Smith, R. Scharroo, J. F. Luis, and F. Wobbe (2013). Generic Mapping Tools: Improved version released, Eos Trans. AGU 94, 409-410

Wittlinger, G., Vergne, J., Tapponnier, P., Farra, V., Poupinet, G., Jiang, M., et al. (2004). Teleseismic imaging of subducting lithosphere and Moho offsets beneath western Tibet. Earth and Planet. Sc. Lett., 221(1), 117-130.

Yao, H., Beghein, C., Van Der Hilst, R. D., 2008. Surface wave array tomography in SE Tibet from ambient seismic noise and two-station analysis - II. Crustal and upper-mantle structure. Geophy, J. Int. 173(1): 205-219.

Yin, A., (2006).Cenozoic tectonic evolution of the Himalayan orogen as constrained by alongstrike variation of structural geometry, exhumation history, and foreland sedimentation.Earth Sci. Rev., 76, 1-131. 


\section{Appendix}

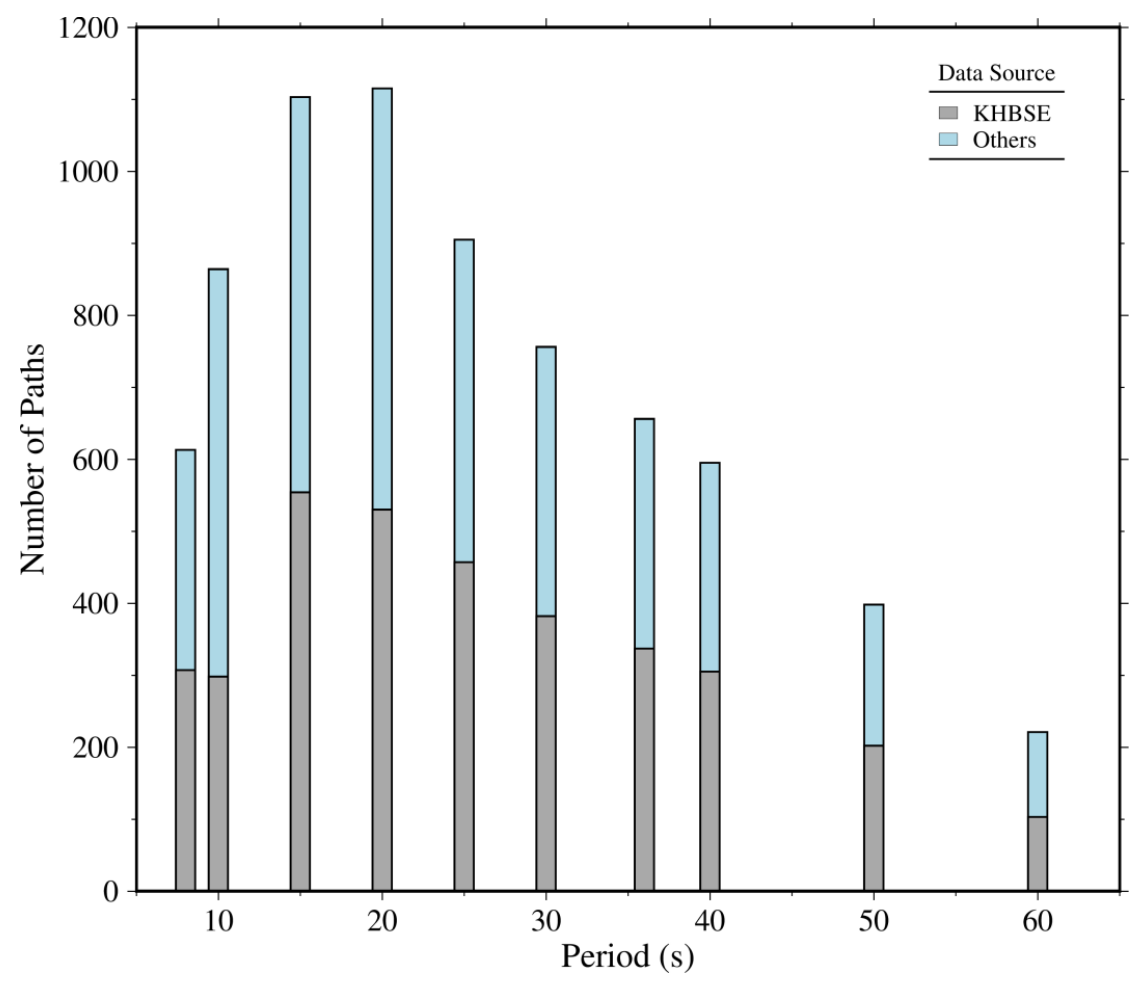

Figure A1: shows the period-dependent availability of data. X-axis denotes the period and $\mathrm{y}$-axis is number of paths. Note that about $50 \%$ of the data originates from Kashmir Himalaya broadband seismic experiment (KHBSE). 

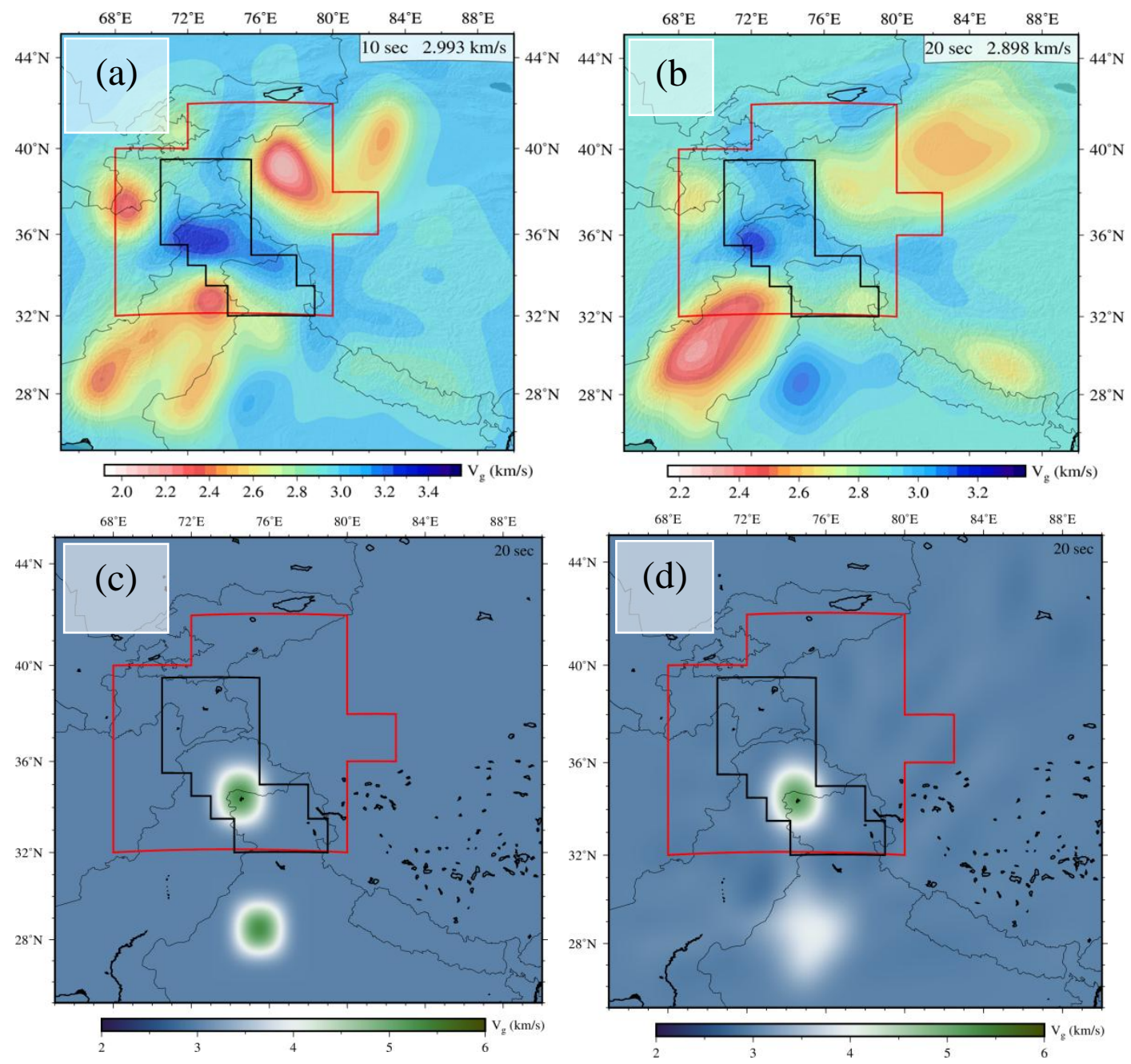

Figure A2 (a) shows fundamental mode Rayleigh wave dispersion map at $10 \mathrm{sec}$ including south of the study region (bounded red polygon). Note a velocity enclave $(\sim 3.1 \mathrm{~km} / \mathrm{s})$ centred about $28^{\circ} \mathrm{N}$ and $75.5^{\circ} \mathrm{E}$, with a slightly higher velocity $(\sim 3.25 \mathrm{~km} / \mathrm{s})$ on $20 \mathrm{sec}$ map (b), which geographically coincides with the location of Aravalli craton. To check this possibility, we carried out a spike test. The input model, with a positive spike at this point and an another spike centered NW of Kashmir, in the well resolved area is shown in (c) and (d) shows the corresponding inverted solution. Whilst the recovery of the Aravalli centred spike is only in the form of a diffused halo as expected from its location, its unmistakable identification with the 
northwestern core of the Aravalli craton at least up to periods of 20 seconds, testifies to the robustness of the dispersion maps.
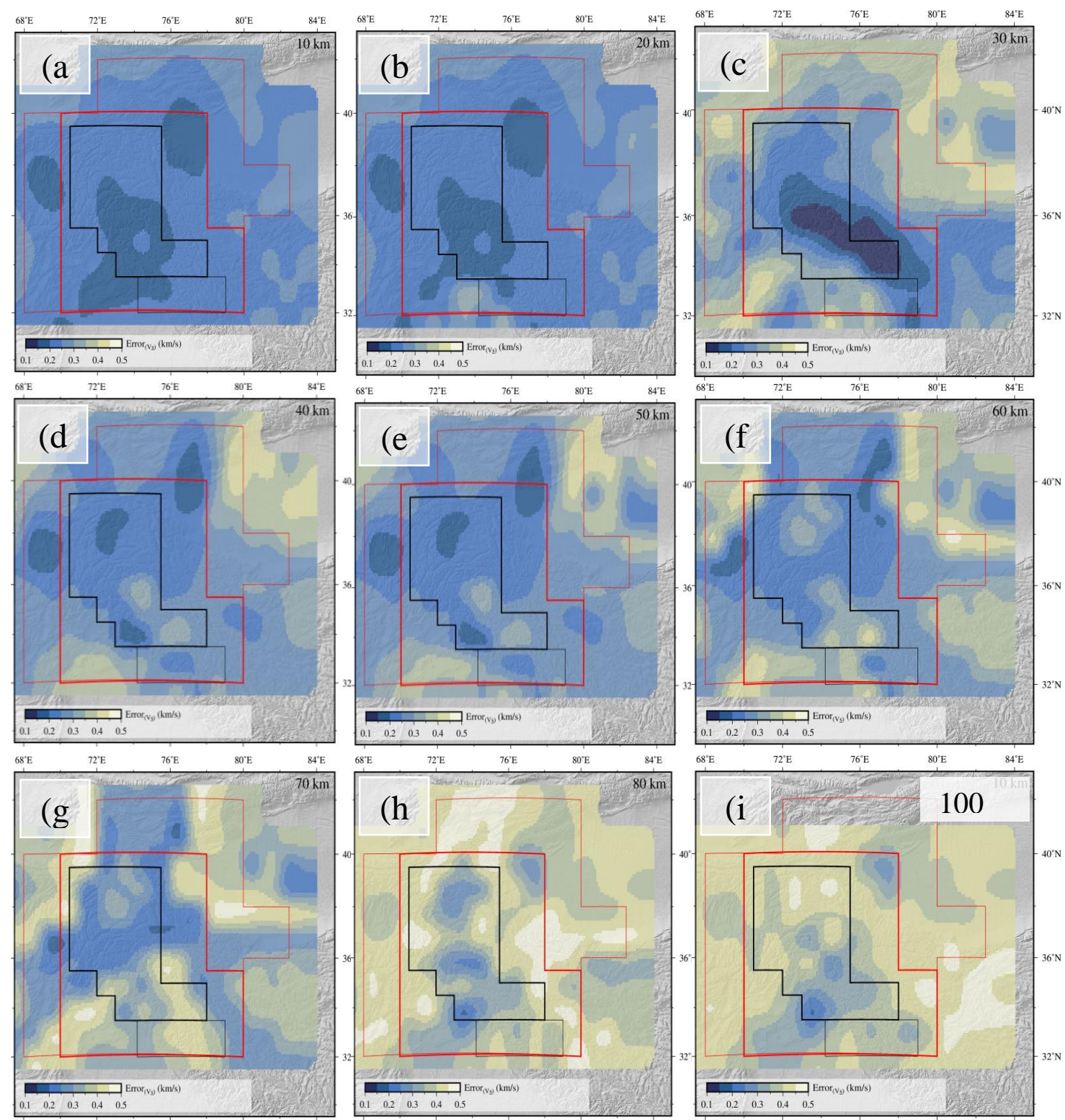

Figure A3: shows posterior Vs errors for shear wave velocity maps shown in Figure 6 of main text. Note the lesser errors $(<0.2 \mathrm{~km} / \mathrm{s})$ at $30 \mathrm{~km}$ depth (c) which corresponds to intra-crustal low velocity layer beneath the NW Himalaya and Hindu Kush. 

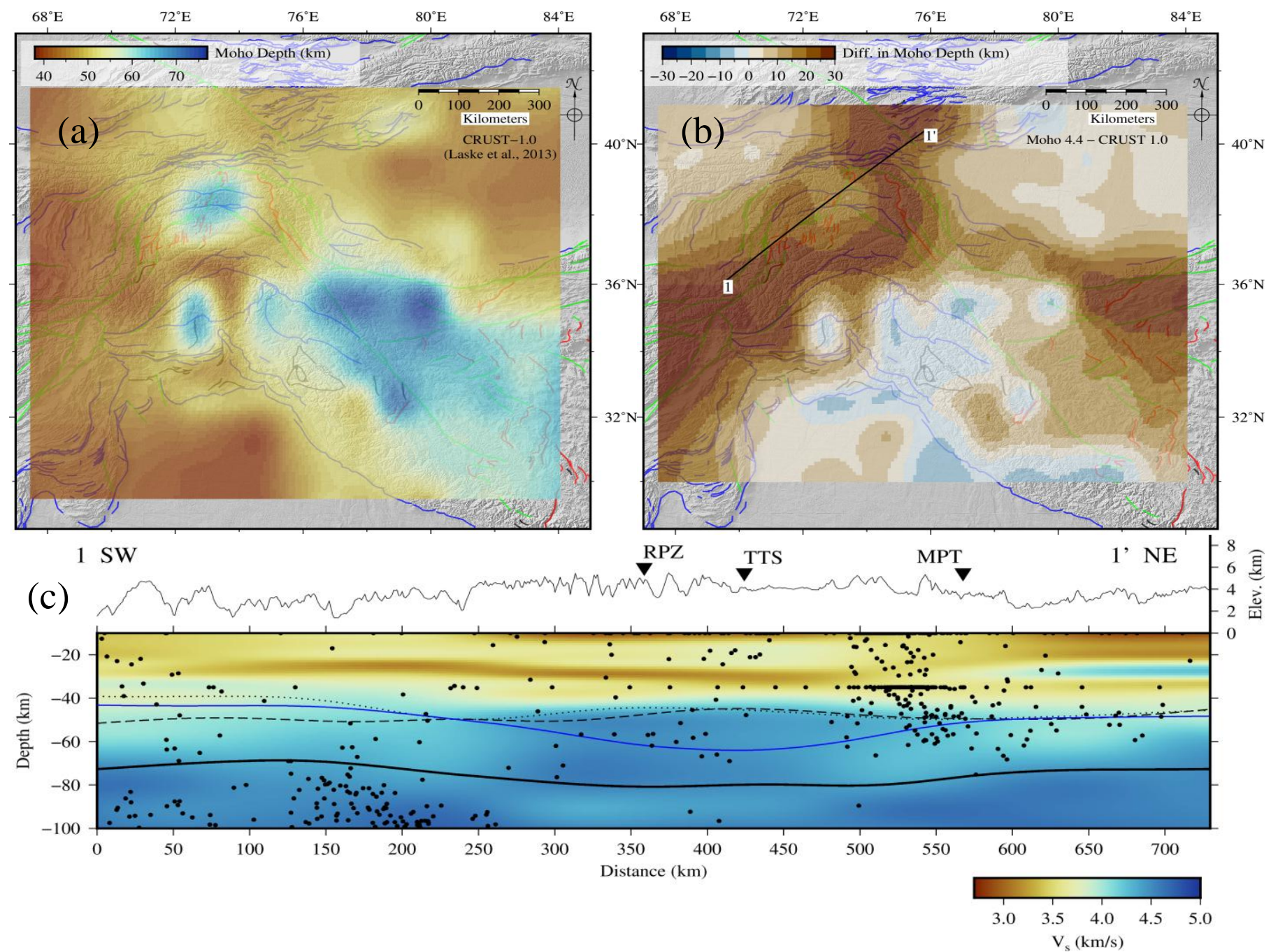

487 Figure A4: (a) shows Moho depth estimates for the region from global crustal model CRUST

4881.0 (Laske et al. 2013). Note the deeper Moho estimates for regions like north-central Pamirs,

489 Hindu Kush and Tibet. (b) shows the Moho difference map produced by subtracting depths given

490 in (a) from posterior Moho estimates obtained in the current study (Figure 7). Except Pamir,

491 Hindu Kush and western Tibet, Moho estimates are within $10 \mathrm{~km}$. (c) shows Vs cross-section

492 along profile 1-1' (same as Figure 9a of main text) with Moho from CRUST 1.0 marked as blue

493 line. Schneider (2014) has reported deeper Moho (up to $85 \mathrm{~km}$ ) beneath the Pamirs, using

494 teleseismic receiver functions generated from locally deployed seismometers, closer to our

495 estimate (Figure 7 of main text). Schneider (2014) also mentioned that due to complex 
496 subduction process in the Pamirs, many previous studies have mistaken Moho as a lower crustal 497 layer, hence underestimating it. 